\title{
Discussion on the Waterproof and Drainage System of the Coastal Tunnel and Analysis of Water Pressure Law outside Lining: A Case Study of the Gongbei Tunnel
}

\author{
Jinpeng Zhao $\mathbb{D}$, ${ }^{1,2}$ Zhongsheng Tan $\mathbb{D}^{1,2}$ and Zhenliang Zhou $\mathbb{D}^{1,2}$ \\ ${ }^{1}$ School of Civil Engineering, Beijing Jiaotong University, Beijing 100044, China \\ ${ }^{2}$ Key Laboratory for Urban Underground Engineering of Ministry of Education, Beijing Jiaotong University, \\ Beijing 100044, China \\ Correspondence should be addressed to Jinpeng Zhao; 18115060@bjtu.edu.cn
}

Received 4 November 2020; Revised 7 February 2021; Accepted 13 February 2021; Published 27 February 2021

Academic Editor: Filippo Ubertini

Copyright ( 2021 Jinpeng Zhao et al. This is an open access article distributed under the Creative Commons Attribution License, which permits unrestricted use, distribution, and reproduction in any medium, provided the original work is properly cited.

With the orderly promotion of the infrastructure construction in China, the number of coastal tunnels is increasing, but the coastal environment is accompanied by a large amount of groundwater and the designs of the waterproof and drainage system of coastal tunnels have always been a hot topic in the industry. If the waterproof and drainage system designs of the coastal tunnels are improper, the tunnel structure will easily be damaged and the stability and service life of the whole project will be affected. Based on the Gongbei tunnel project of the Hong Kong-Zhuhai-Macao Bridge, this paper discusses the designs of the waterproof and drainage system, and the waterproof detail structures of the Gongbei tunnel. Indoor similarity tests were carried out to study the law of the free water discharge of the tunnel under variable water heads, the relationship between the water pressure outside the lining and the water discharge, the relationship between the water pressure outside the pipe roof and the water discharge, and the distribution of water pressure around the tunnel. The reliability of the indoor similarity test was verified by the field test. The results show that the whole waterproof system should be adopted in the Gongbei tunnel, that is, grouting ring + pipe roof freezing ring + initial lining + waterproof board + tertiary lining. In a certain range, the greater the water head, the greater the free water discharge of the tunnel. When the water head is large, the free drainage tends to a fixed value. When the tunnel is completely plugged, the water pressure outside the tunnel is distributed from the hydrostatic pressure. When the tunnel adopts drainage measures, the water pressure outside the lining will be reduced to a certain extent even the water discharge is very small. The above research can provide a reference for the design of the waterproof and drainage system similar to the coastal tunnel in the future.

\section{Introduction}

With the orderly progress of the infrastructure construction in China, a large number of coastal tunnels have emerged $[1,2]$. The stratum of the coastal tunnel is rich in groundwater, and it is corrosive. The geology of the coastal tunnel is very complex and the water pressure is very high, which may cause some construction risk for the tunnel, such as water seepage, ground instability, and equipment failure $[3,4]$. Thus, a reasonable design of the tunnel waterproof and drainage system can effectively prevent the infiltration of seawater, protect the safety of the tunnel structure, and prolong the service life of the project. If the tunnel waterproof and drainage system design is not reasonable, it may cause the sea water to seep into the tunnel, make the tunnel lining fall off, and shorten the project life $[5,6]$. In addition, the infiltration of the seawater also poses a certain risk of damage to the exhaust equipment in the tunnel [7]. Therefore, the rationality and reliability of the waterproof and drainage system is the key to the successful construction and safe operation of the coastal tunnel. The tunnel is in the coastal environment, and once a leakage occurs, the consequences and hazards are difficult to deal with. Therefore, engineers often favor the concept of limited drainage or full plugging. It is also very important to study the size and the distribution of the water pressure outside the lining so as to 
assess whether it is the limited drainage or full plugging. The size and distribution of the water pressure had a great impact on the internal force of lining [8]. If the reasonable water pressure outside the lining can be determined, it can provide the basis for the consideration of water load in the lining design of the coastal tunnel and prevent the occurrence of unreasonable lining designs [9].

For the designs of the waterproof and drainage system of the coastal tunnel, the principle of the waterproof and drainage design should be determined first; that is, the principle of full plugging, full drainage, or limited drainage should be adopted, and then the designs of the waterproof and drainage system can be carried out. China's "Technical Code for Waterproof of Underground Engineering" puts forward the general treatment principle for the waterproofing of the underground engineering; that is, "combining prevention, drainage, interception and plugging, adjusting measures to local conditions and comprehensive treatment" [10]. However, different methods were adopted for different types of tunnels in Japan [11]. The waterproof system of the mountain tunnels is mainly based on the principle of drainage and a combination of plugging and drainage. Urban subway and subsea tunnel mainly adopt the principle of plugging and combining plugging with drainage. Relevant scholars have done a lot of research and analysis [12, 13], and the principle of full plugging was mainly applicable to tunnels with small cover depth or low groundwater level, and there are few practical application projects. The principle of limited drainage was mainly used in mountainous tunnels with high groundwater level, such as the Yuanliangshan tunnel [14], and underwater tunnels with difficult drainage, such as the Jiaozhouwan tunnel [15] and the Xiangan tunnel [16]. Due to our attention to environmental problems in recent years, the principle of full drainage does not meet the requirements of the current national sustainable development, and the application of engineering examples is decreasing.

Some scholars have studied the water pressure outside the tunnel lining. The water pressure outside the tunnel lining is mainly controlled by drainage conditions, grouting ring thickness, season, and the surrounding rock permeability. Reasonable drainage measures can effectively reduce the water pressure outside the lining, but the degree of water pressure reduction at different positions outside the lining varies [17-19]. The larger the grouting ring is in a certain range, the smaller is the water pressure outside the tunnel lining. However, economic and construction factors should be considered to determine a reasonable thickness of the grouting ring [20, 21]. The smaller the permeability of surrounding rock is, the smaller the external water pressure of the tunnel lining is. In fact, the grouting ring can reduce the water pressure outside the lining mainly because of the change of the surrounding rock permeability [22, 23]. In addition, seasons also have a certain influence on the water pressure outside the lining, and the rainy season is generally accompanied by greater water pressure [24, 25]. However, the above research results were basically concentrated in the mountain tunnels and the karst tunnels, and there was little research on the water pressure outside the lining of the coastal tunnel.

This paper takes the Gongbei tunnel project as the research object, discusses the principle of the drainage and the composition of the drainage system of the coastal tunnel. In this paper, the distribution of water pressure behind the pipe roof and lining was studied by means of similar indoor test under the conditions of full plugging, limited drainage, and full drainage. The free water discharge of the tunnel under variable water heads was also studied. Combined with the field monitoring method, the distribution characteristics of water pressure outside the initial support and inside the waterproof board of the Gongbei tunnel were analyzed. The above study aims to provide reference for the design of the waterproof and drainage system of coastal tunnel engineering.

\section{Description of the Analyzed Tunnel Project}

2.1. Location and Scale of the Tunnel. The Gongbei tunnel, a key project of the Zhuhai connecting line of the Hong Kong-Zhuhai-Macao Bridge, is a coastal tunnel, which was fully completed on February 24, 2018. The tunnel starts from the Gongbeiwan Area, connects the Gongbeiwan Bridge and ends at the Maoshengwei Management Area of the fifth detachment of the border defense, with a total length of $2740 \mathrm{~m}$. In the limited area of the port, the curve freezing pipe roof was adopted for the advanced support, and the underground excavation method was adopted. The length of the excavation section is $255 \mathrm{~m}$. Two shafts were set on both sides of the port, as shown in Figure 1. The underground excavation section was designed as double-layer, two-way and three-lane, $23.84 \mathrm{~m}$ high and $22.24 \mathrm{~m}$ wide, and the cross section is oval, as shown in Figure 2. The average passenger flow through the Gongbei Port above the tunnel is about 400000 per day. There are many buildings and infrastructure around the tunnel, such as the Gongbei Port and its ancillary buildings, the Zhuhai Railway Station, power pipelines, water supply pipelines, and communication pipelines. In such a complex environment, the waterproof and drainage system of the tunnel must be designed reasonably.

2.2. Engineering Geology. From top to bottom, the stratums of the Gongbei tunnel are mainly composed of (1) artificial fill, (3)-1 muddy soil, (3)-2 silty clay, (3)-3 gravel sand layer, (4)-3 muddy clay, (5)-1 silty clay, (5)-2 medium sand layer, (5)-3 muddy clay, (6)-2 coarse sand layer, (7)-1 sandy clay, and (8)-1 weathered granite. The underground water level is $2 \mathrm{~m}$ below the ground surface, $5.2 \mathrm{~m}$ away from the upper edge of the tunnel pipe roof, as shown in Figure 3. Table 1 shows the physical and the mechanical parameters of the stratums where the tunnel is located. It can be seen that the stratum strength is low, the overall permeability is relatively good, and the engineering geological conditions are poor. Waterproofing should be paid attention to in the design and 


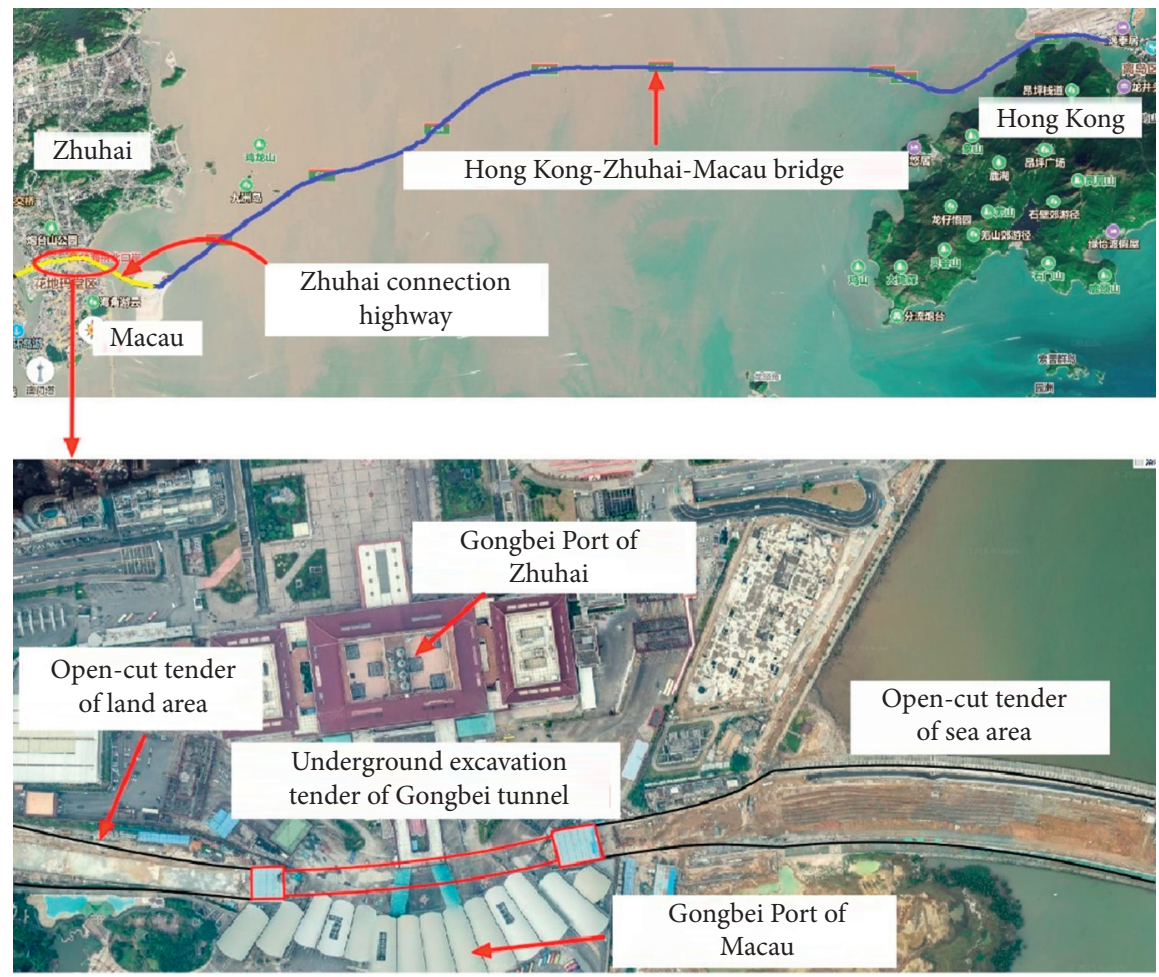

FIGURE 1: Location plan of the Gongbei tunnel.

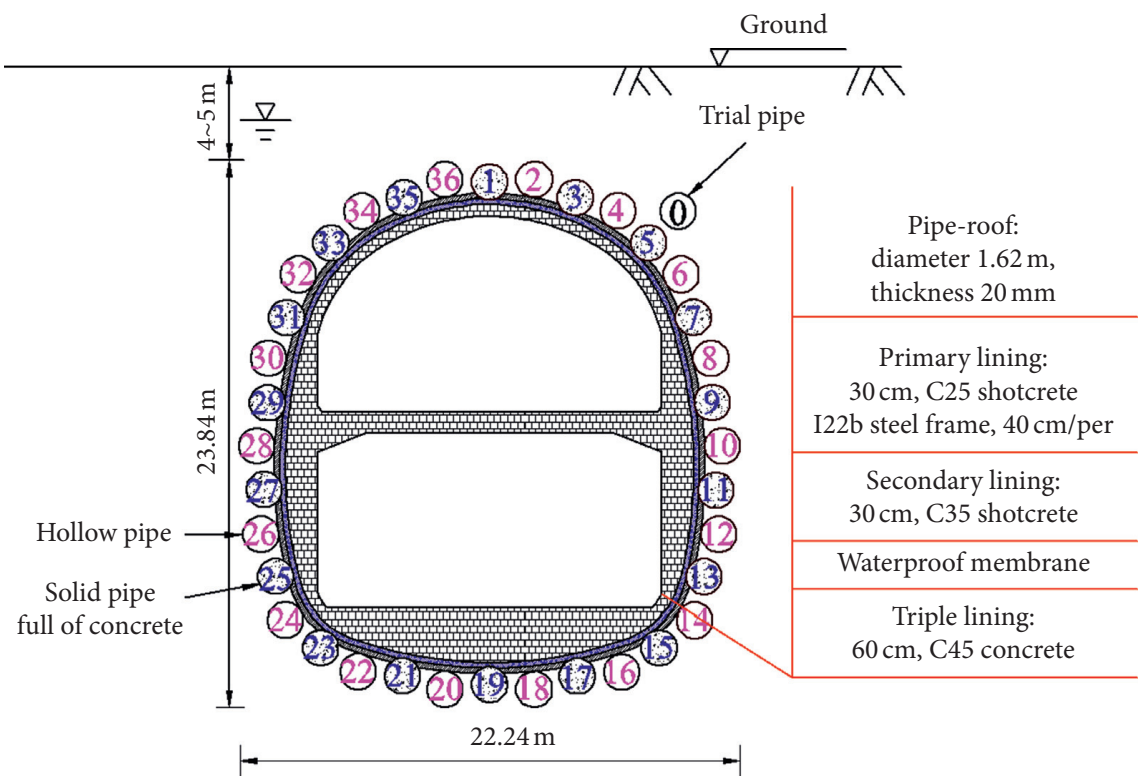

Figure 2: Schematic diagram of the Gongbei tunnel section and the supporting structure.

construction to reduce the impact on the tunnel structure and the surrounding environment.

\section{Waterproof and Drainage System of the Gongbei Tunnel}

The Gongbei tunnel is close to the sea with a large cross section and poor engineering geology. If the drainage principle or the limited drainage principle is adopted, the water will carry away the fine soil particles, which will lead to a cavity behind the tunnel lining, affect the long-term safety of the tunnel, and also have a certain impact on the surrounding environment of the tunnel [26-28]. In addition, if the drainage principle or the limited drainage principle is adopted, the tunnel drainage capacity should be higher; however, the water discharge of the tunnel is large and the water source is stable, so the underground water in the tunnel cannot be drained $[29,30]$. Finally, due to the shallow 


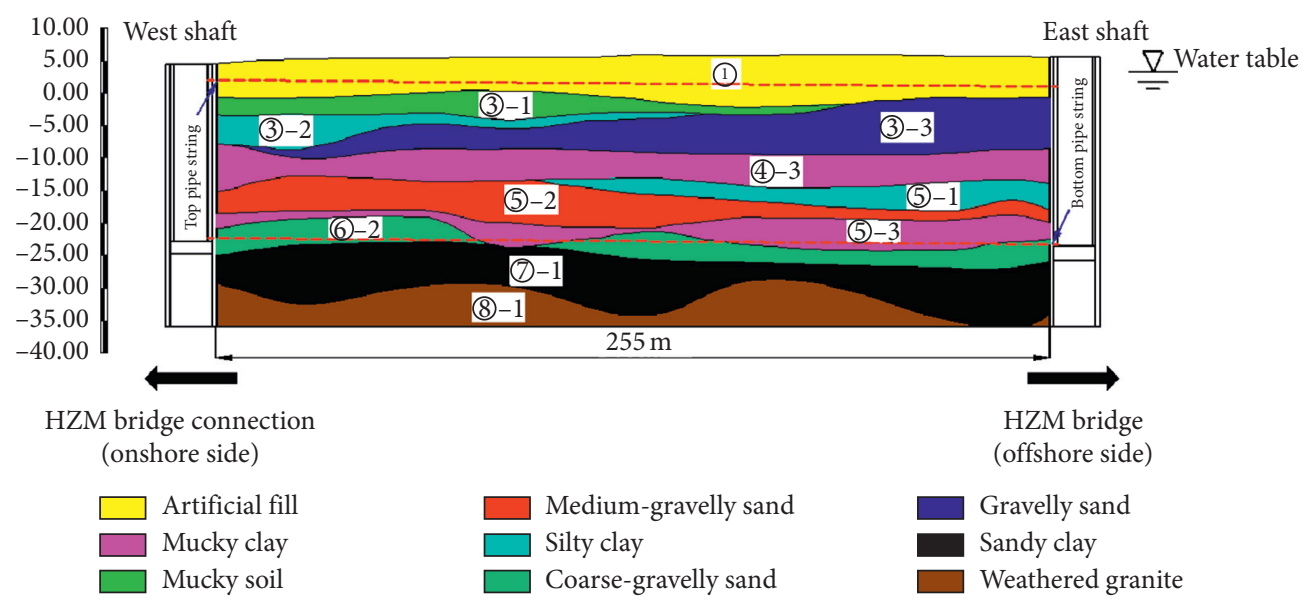

Figure 3: Geological profile of the Gongbei tunnel.

TABLe 1: Physical and mechanical parameters of the stratum.

\begin{tabular}{|c|c|c|c|c|c|c|}
\hline Layer & Soil & Thickness (m) & Compressive modulus (MPa) & $\begin{array}{l}\text { Density } \\
\left(\mathrm{g} / \mathrm{cm}^{3}\right)\end{array}$ & Void ratio & Permeability coefficient $(\mathrm{cm} / \mathrm{s})$ \\
\hline (1) & Artificial fill & $5.3-8.1$ & 5.22 & 2.25 & 0.95 & $9.16 \times 10^{-5}$ \\
\hline (3) -1 & Mucky soil & $2.1-3.2$ & 2.22 & 1.75 & 1.32 & $4.97 \times 10^{-8}$ \\
\hline (3) -2 & Silty clay & $0-5.4$ & 4.91 & 1.98 & 0.71 & $1.82 \times 10^{-5}$ \\
\hline (3) -3 & Gravelly sand & $0-8.5$ & 4.53 & 1.95 & 0.55 & $5.85 \times 10^{-2}$ \\
\hline (4) -3 & Mucky clay & $2.6-4.8$ & 4.21 & 1.88 & 0.98 & $9.61 \times 10^{-8}$ \\
\hline (5) -1 & Silty clay & $0-4.4$ & 5.19 & 1.95 & 0.78 & $1.74 \times 10^{-5}$ \\
\hline (5) -2 & Medium-gravelly sand & $1.4-7.1$ & 4.60 & 2.05 & 0.45 & $7.35 \times 10^{-3}$ \\
\hline (5) -3 & Mucky clay & $0.6-4.9$ & 3.53 & 1.81 & 1.11 & $5.78 \times 10^{-8}$ \\
\hline (6) -2 & Coarse-gravelly sand & $0-4.2$ & 4.53 & 1.95 & 0.55 & $6.92 \times 10^{-2}$ \\
\hline (7)-1 & Sandy clay & $0.5-9.3$ & - & 1.76 & 1.09 & - \\
\hline (8) -1 & Weathered granite & $>20$ & - & - & - & - \\
\hline
\end{tabular}

buried depth of the tunnel and the small water pressure, the effect on the internal force of the structure is limited. To sum up, combined with the experience of tunnel waterproofing and drainage technology in China [14], it is considered that the Gongbei tunnel should adopt the principle of "prevention first." After a lot of investigation and summary [31], the components of the Gongbei tunnel waterproof system were determined, including grouting ring, pipe roof freezing ring, initial support, secondary lining, waterproof board, and tertiary lining.

3.1. Grouting Ring. Grouting is one of the means to waterproof a tunnel. In this method, grout is used to replace the water existing in cracks and pores, block the path of the groundwater, restrict the migration of the groundwater, and form rock and soil with certain impermeability to ensure the stability of the surrounding environment of the tunnel. Grouting waterproofing does not mean that the added solid is dripping impervious through grouting, but more emphasis is placed on reducing the adverse impact of water on the construction and the structure through grouting [32, 33].

The grouting scheme adopted for the Gongbei tunnel is as follows: the grouting holes were reserved on the steel pipes of the pipe roof, the grouting holes were arranged according to the principle of curtain grouting, and the grouting was conducted in each steel pipe. All grouting holes were grouted along the radial direction of the steel pipes to form a water stop curtain around the whole pipe roof. The thickness of the water stop curtain was about $3 \mathrm{~m}$ outside the steel pipes, as shown in Figure 4 . The grouting material was ultrafine cement water glass slurry, the ratio of water to cement was $1: 1$, and water glass with 35 Baume degrees was used. The grouting pressure was $0.6-1.2 \mathrm{MPa}$, and the grouting speed was $20-40 \mathrm{~L} / \mathrm{min}$. In addition to the grouting outside the pipe roof described above, the grouting process of the Gongbei tunnel also includes grouting behind the initial support and grouting behind the secondary lining.

3.2. Pipe Roof Freezing Ring. The freezing method is to use artificial refrigeration technology to freeze the water in the stratum, turn the loose water-bearing rock and soil into frozen soil, increase its strength and stability, and isolate groundwater, so as to carry out underground engineering excavation and construction under the protection of the freezing wall. It is a physical reinforcement method of the soil layer and a temporary reinforcement technology. When the engineering needs, the frozen soil can have rock-like 


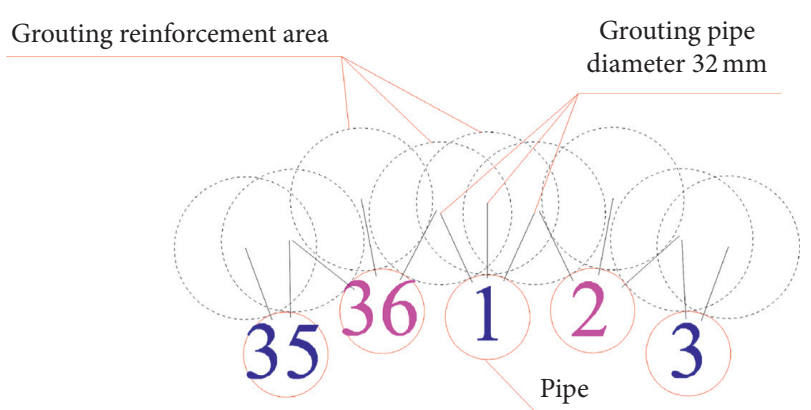

FIGURE 4: Schematic diagram of grouting for water plugging in the Gongbei tunnel.

strength. If the reinforcement strength is not required, the forced thawing technology can be employed to make it melt [34].

The freezing layer of the pipe roof was mainly used for waterproofing during construction, because the soil would be thawed after the construction of the tunnel. In the Gongbei tunnel, 36 steel pipes with a diameter of $1620 \mathrm{~mm}$ were used to form a pipe roof. The soil mass of about $35.7 \mathrm{~cm}$ between the steel pipes was frozen by a freezing method. The thickness of the frozen soil was $2 \mathrm{~m}$, as shown in Figure 5. Two circular freezing pipes with a diameter of $133 \mathrm{~mm}$ were used as the main cold source in odd pipe jacking, as shown in Figure 6. A limit pipe was set near the outer edge of the frozen soil curtain and filled with concrete. In order to achieve dynamic control of freezing, a semi-circular specialshaped freezing pipe with a diameter of $159 \mathrm{~mm}$ was set in the even pipe jacking to strengthen the freezing, so as to restrain the influence of air heat exchange on frozen soil. The schemeof the overall positive freezing and the sectional maintenance freezing was adopted to ensure the water sealing effectiveness of the frozen soil curtain which plays the major role in waterproofing during the tunnel excavation [35].

3.3. Initial Support. For ordinary tunnels, the initial support is generally the first line of defense for tunnel waterproofing. In the initial support, a certain amount of waterproof material can be added to the shotcrete to increase the waterproof performance of the initial support. However, in the actual engineering, the initial support will have certain leakage [7], so the waterproof capacity of the initial support is limited.

The initial support of the Gongbei tunnel is composed of C25 shotcrete and I22b I-steel arch. The longitudinal spacing of I-steel is $0.4 \mathrm{~m}$, and the initial support thickness is $30 \mathrm{~cm}$. The two ends of the initial support I-steel were welded with odd number pipes, and the middle part was welded with even number pipes to form a closed support system, as shown in Figure 2, and I16 I-steel was used for the longitudinal connection. A BR-2 type waterproof agent was added into the shotcrete with a content of $3-4 \%$ of the cement mass, and the grouting shall be carried out for the voids behind the shotcrete in time before the construction of the secondary lining to prevent the formation of cavities and water sacs.

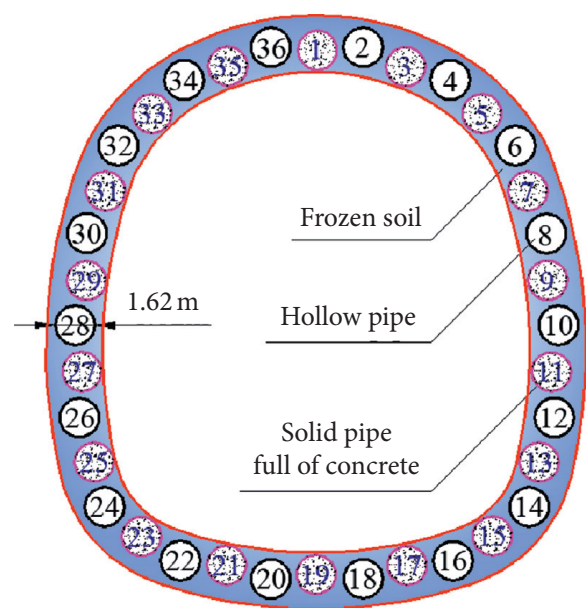

Figure 5: Schematic diagram of the pipe roof freezing ring.

3.4. Secondary Lining. The waterproof effect of the secondary lining is similar to that of the initial support, which belongs to concrete waterproof. C35 shotcrete was used at the vault of the secondary lining of the Gongbei tunnel, and C35 light steel frame formwork concrete was used for other parts of the secondary lining, with a thickness of $30 \mathrm{~cm}$. The grid steel frame was welded with $25 \mathrm{~mm}$ diameter steel bars, with a section size of $19.16 \mathrm{~cm} \times 14.38 \mathrm{~cm}$, and the segments are mechanically connected with each other. The grid steel frame was divided into sections and erected according to the excavation process of the tunnel steps. Each steel bar grid was assembled and erected in 12 sections. The grouting hole was reserved in the secondary lining, and the grouting pressure was 1.5-2.0 MPa. The gap between the initial support and the secondary lining was filled to prevent the water from converging to form a water bag, which would affect the lining safety.

3.5. Waterproof Board. The Gongbei tunnel adopted the fully plugging system, the waterproof board was arranged between the secondary lining and the tertiary lining, and the whole section was covered with the waterproof layer. There were no longitudinal drainage pipes and circular permeable pipes outside the waterproof layer. The waterproof layer was made of $1.5 \mathrm{~mm}$ thick pre-laid HDPE film composite waterproof membrane, with $400 \mathrm{~g} / \mathrm{m}^{2}$ nonwoven fabric, as shown in Figure 7.

3.6. Tertiary Lining. Compared with the initial support and the secondary lining, the tertiary lining structure has better integrity and less leakage. The thickness of arch is $60 \mathrm{~cm}$, the thickness of invert is $64.5-218.6 \mathrm{~cm}$, and the thickness of the side wall is $60-150 \mathrm{~cm}$, as shown in Figure 2. The tertiary lining was poured in three times. Firstly, the inverted arch was poured, then the middle plate and the side wall at the lower part of the middle plate were poured, and finally the upper structure of the middle plate was poured. The upper structure of the tertiary lining was constructed by formwork trolley, and the sectional length of the trolley is $6 \mathrm{~m}$. The tertiary lining was made of waterproof concrete with 


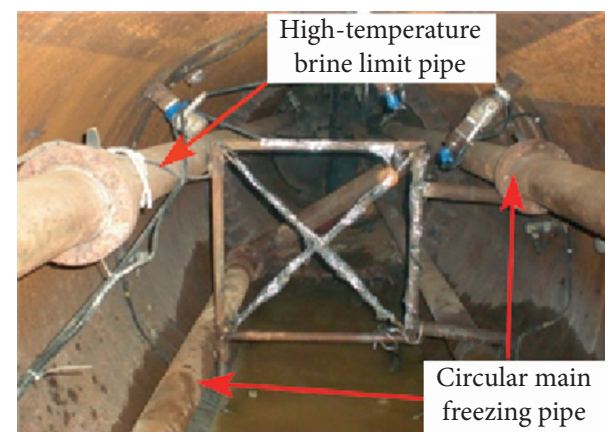

FIGURE 6: Arrangement of freezing pipes and limiting pipes in the steel pipe of the pipe roof.

impermeability grade of $\mathrm{P} 10$ and erosion resistance coefficient of 0.84 .

\subsection{Detail Waterproof Structure}

3.7.1. Construction Joints. The circumferential construction joints of the tunnel excavation section are determined based on the length of the tertiary lining pouring, and one is set every $6 \mathrm{~m}$. Two waterproof measures were set at the construction joints except for the medium plate, as shown in Figure 7. The outer side of the tertiary lining was laid with $1.5 \mathrm{~mm}$ thick HDPE film composite waterproof membrane and its strengthening layer, and the middle part was set with steel edge waterstop.

The longitudinal construction joints of the tunnel excavation section adopted two waterproof measures: setting steel-edge rubber waterstop and brushing cement-based permeable crystal waterproof coating. Before that, the longitudinal construction joints shall be roughened, as shown in Figure 8.

3.7.2. Deformation Joints. Four deformation joints were set in the underground excavation section of the Gongbei tunnel, which are $36 \mathrm{~m}$ and $72 \mathrm{~m}$ away from the diaphragm walls of shafts on both sides, as shown in Figure 9. The deformation joint waterproof adopted multiple defense lines, as shown in Figure 10, and four waterproof measures were set. The outer side of the tertiary lining was laid with $1.5 \mathrm{~mm}$ thick HDPE film composite waterproof membrane, and its strengthening layer. A steel-edge rubber waterstop was set at $1 / 3$ of the outer surface of the tertiary lining. Rubber expansion water stop with grouting pipe shall be set at $2 / 3$ of the outer surface of the tertiary lining. The inner side of the tertiary lining was coated with polysulfide two-component sealant.

3.7.3. Waterproof at the Joints of Shafts and the Tunnel Excavation Section. The waterproof measures at the joint of the shafts and the tunnel excavation section are shown in Figure 11. Grouting pipes were arranged near the joint surface of the pipe roof and the diaphragm wall to fill the gap between the pipe roof and the diaphragm wall. The waterproof layer was arranged between the tertiary lining and the secondary lining, and the waterproof measures of this part are consistent with the waterproof board mentioned above. Water swellable strips and grouting pipes were arranged at the junction of the tertiary lining and the diaphragm wall to prevent the waterproof of the joint between the tertiary lining and the diaphragm wall. There was a part of post-pouring strip in the diaphragm wall. Water swelling strips were arranged between the post-pouring strip and the tertiary lining, and water swelling strips and grouting pipe were arranged between the the post-pouring strip and the diaphragm wall.

\section{Indoor Similarity Test Study on Water Pressure Distribution of the Tunnel}

\subsection{Test Designs}

4.1.1. Test Equipment. The Gongbei tunnel model experimental equipment is independently developed by the Tunnel and Underground Engineering Research Center of Beijing Jiaotong University [36], which can exert water pressure and Earth pressure at the same time. The external dimension of the model test rack is $260 \mathrm{~cm} \times 100 \mathrm{~cm} \times 180 \mathrm{~cm}$, as shown in Figure 12. There are four hydraulic jacks on the upper part of the test rack and two hydraulic jacks on both sides, which can be used to apply vertical and horizontal loads. The maximum loading force of each hydraulic Jack is $500 \mathrm{kN}$. The model rack can bear the pressure of $2000 \mathrm{kN}$ vertically and $1000 \mathrm{kN}$ on the left and right sides. The model test control system includes the hydraulic control system, the water pressure control system, the data acquisition system, and the rack structure. The hydraulic control system and the hydraulic pressure control system are shown in Figures 13 and 14, respectively. The hydraulic control system simulates the Earth pressure on the structure by controlling the pressure of the Jack. The water pressure control system is used to increase the water pressure and simulate the water pressure on the structure. Through the water pressure control system, $0-0.5 \mathrm{MPa}$ water pressure can be added on the top surface. Hydraulic control system and water pressure control system are independent of each other. Forty channels of data interface are reserved in the data acquisition system, which can carry out a lot of testing and data processing.

4.1.2. Similarity Criterion. Similarity criterion can be derived by law analysis, dimensional analysis, or equation analysis [37]. In this paper, the dimensional analysis method 


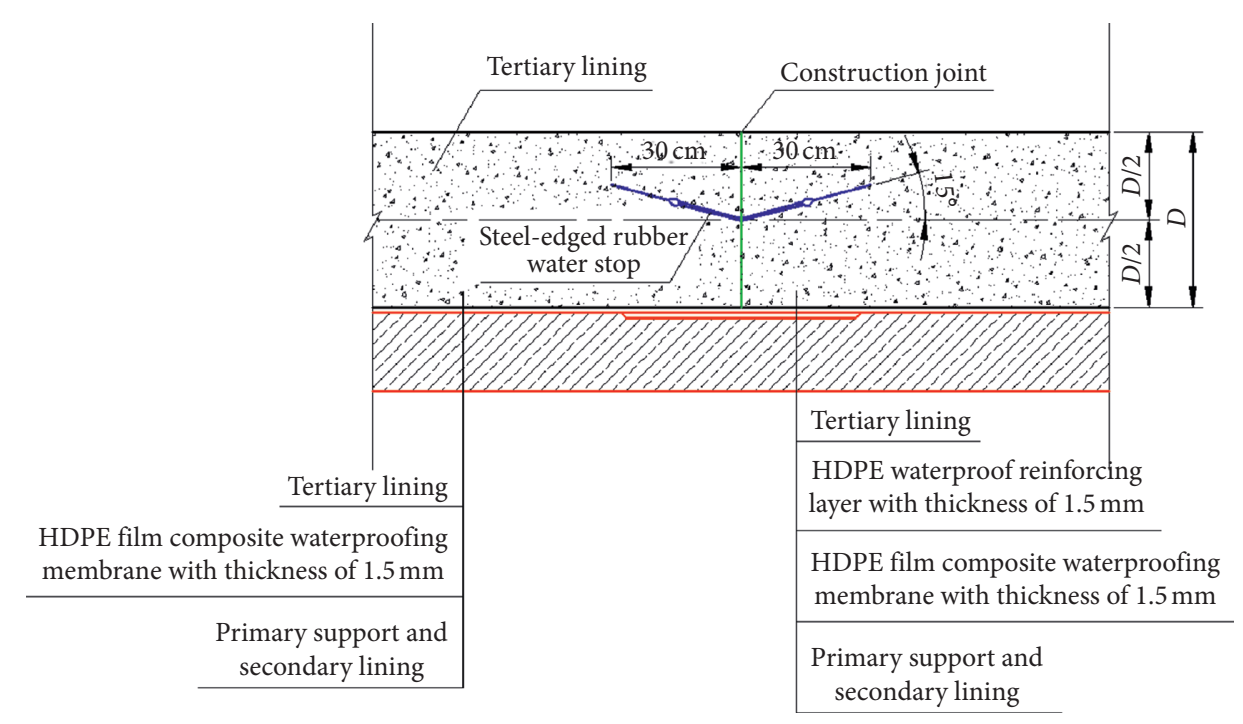

FIGURE 7: Schematic diagram of the waterproof structure of the circumferential construction joints.

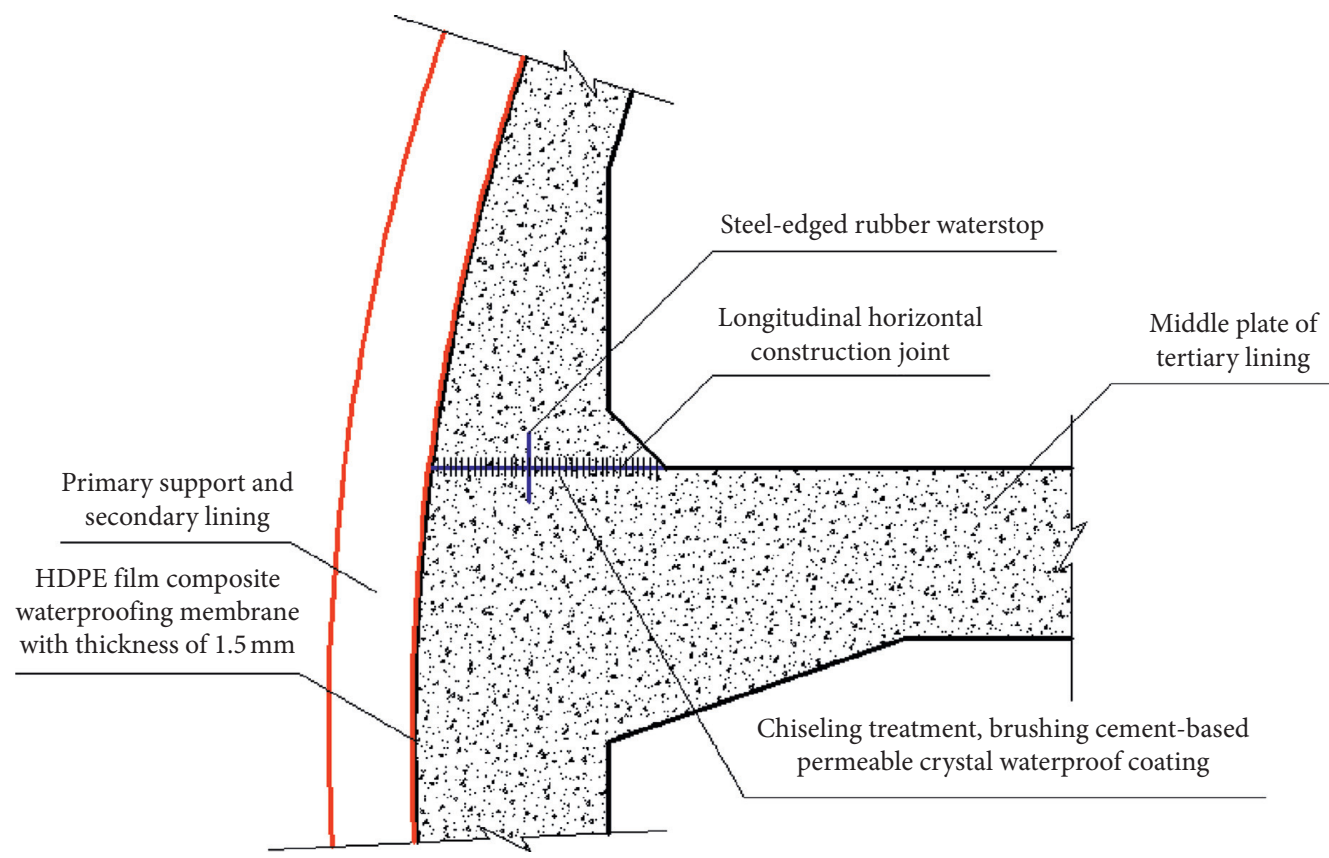

FIGURE 8: Schematic diagram of the waterproof structure of the longitudinal construction joints.

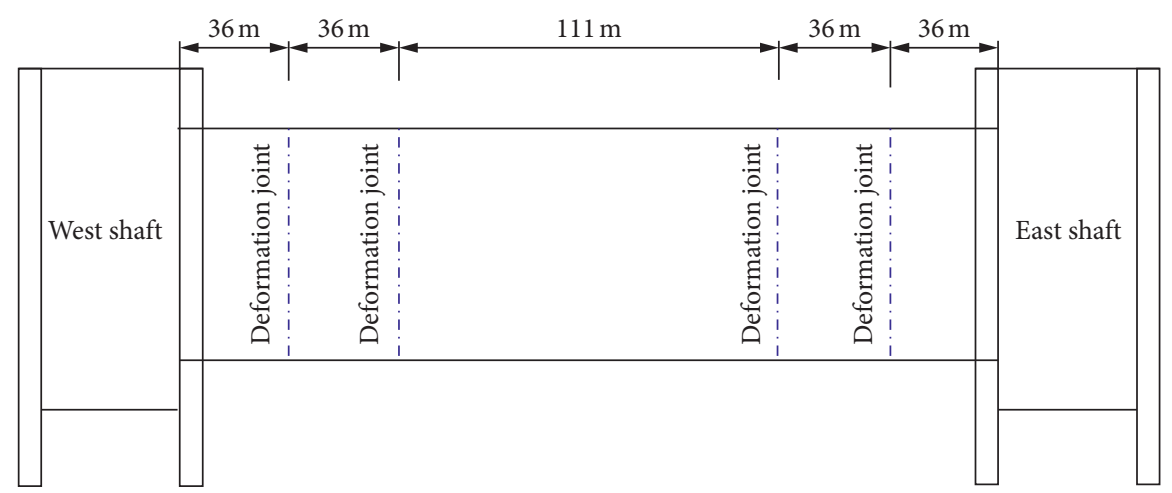

Figure 9: Schematic diagram of the position of the deformation joints in the tunnel excavation section. 


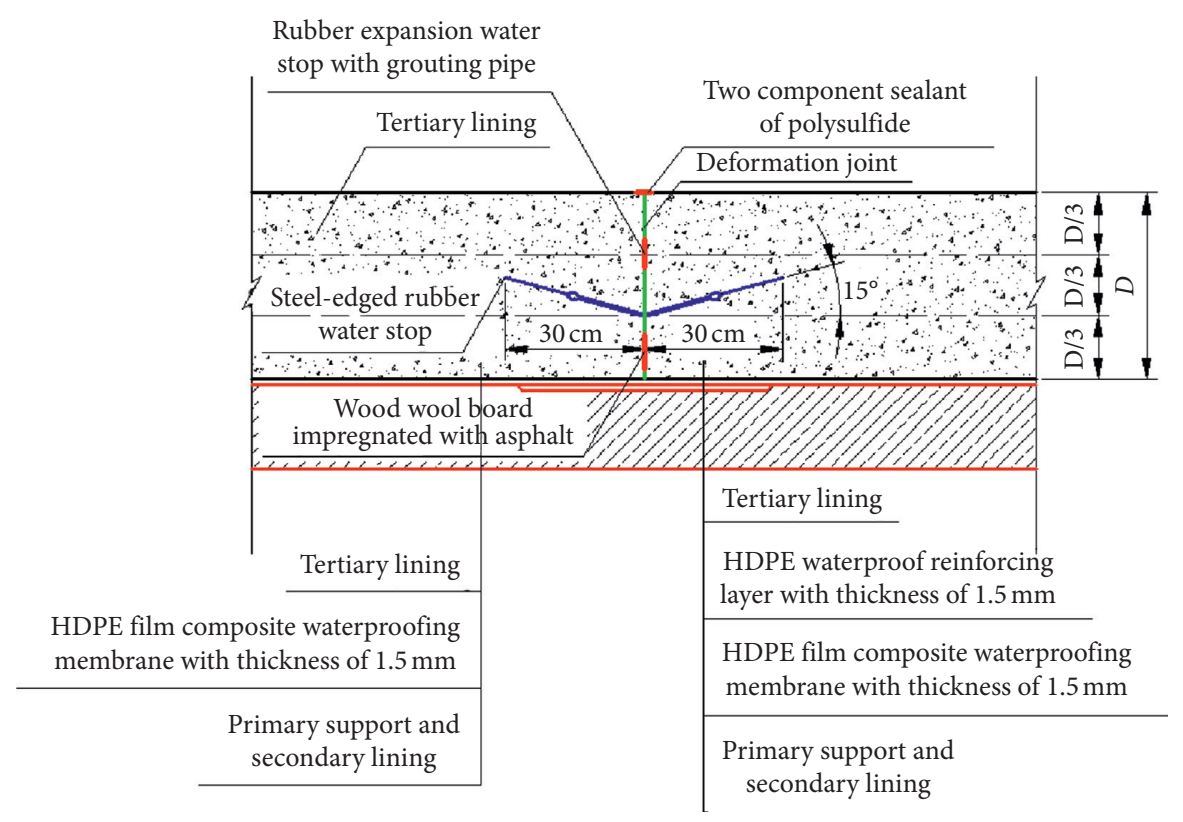

FIGURE 10: Schematic diagram of the waterproof structure of the deformation joints.

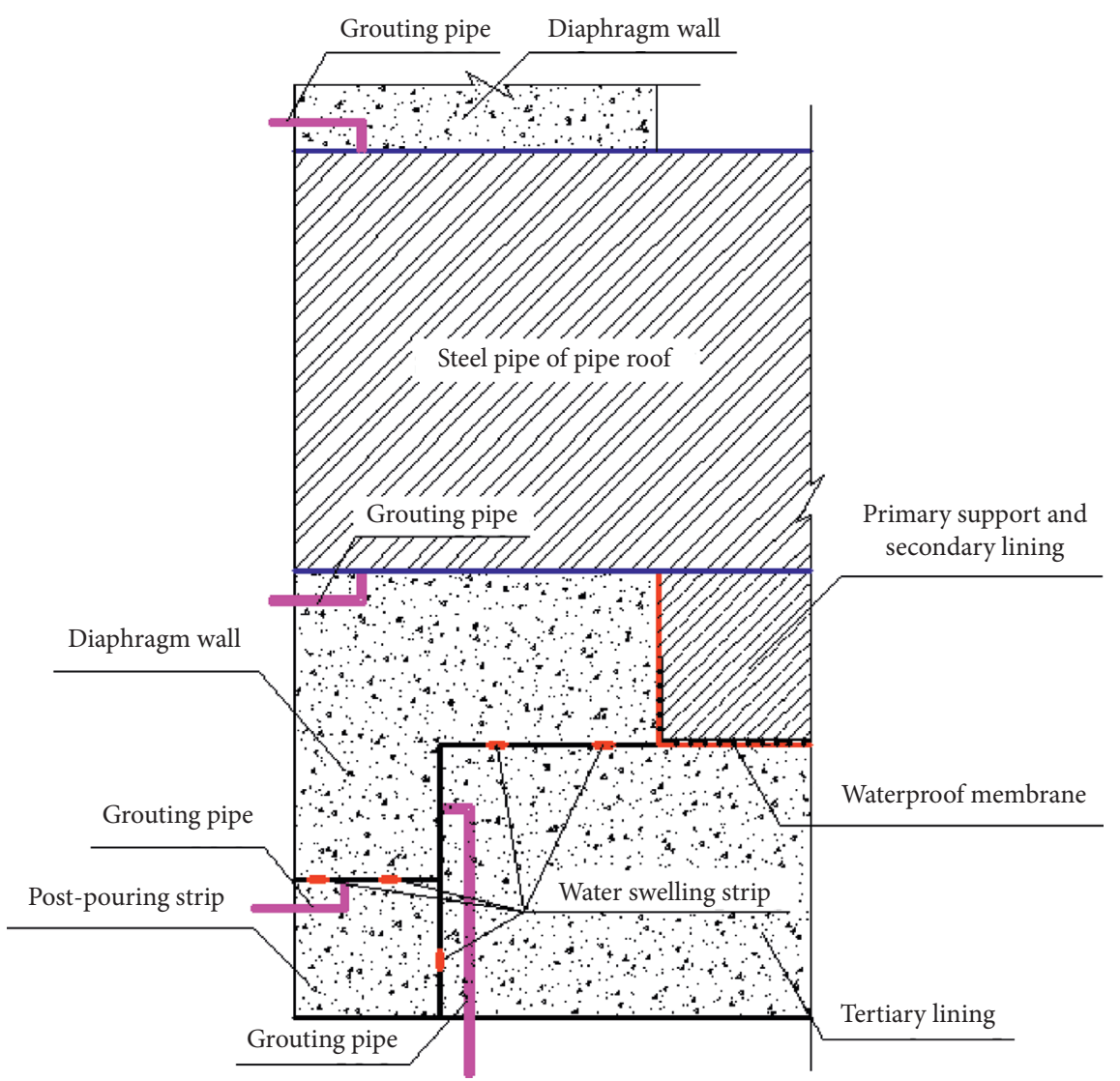

FIGURE 11: Waterproof schematic diagram of the connection between the tunnel excavation section and the shafts.

was adopted, which was based on the second similarity theorem. The calculation table of similarity constants of various physical quantities of the seepage field is shown in Table 2.
It can be seen from Table 2 that the similarity constants of other physical quantities can be calculated as long as the similarity constants of bulk density, geometric dimension, and permeability coefficient were determined. Based on the 


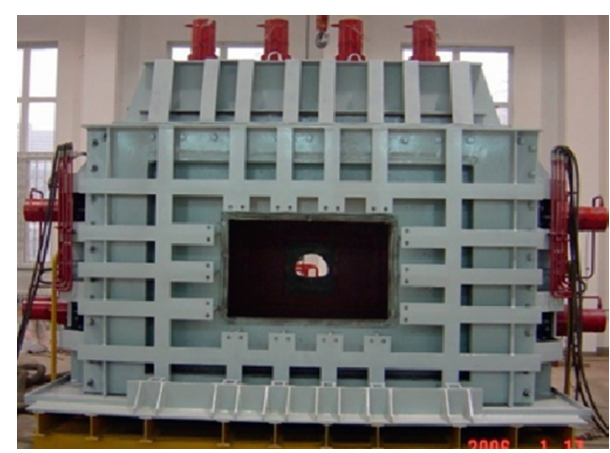

FIGURE 12: Front view of the test rack.

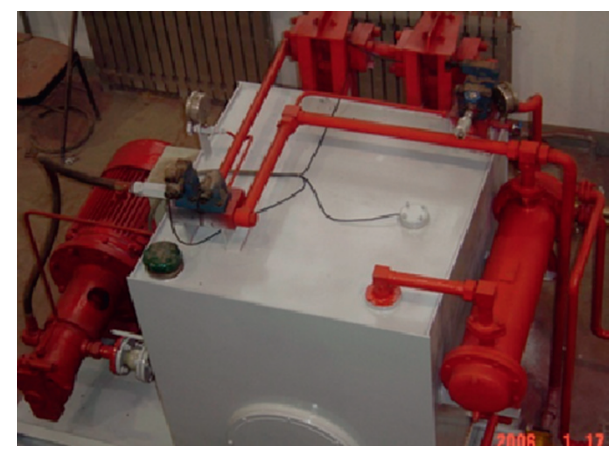

FIgURE 13: Hydraulic control system diagram.

TABLE 2: Calculation table of similarity constants of physical quantities of the stress field and the seepage field.

\begin{tabular}{|c|c|c|c|c|}
\hline $\begin{array}{l}\text { Physical } \\
\text { quantity }\end{array}$ & Symbol & Dimension & $\begin{array}{c}\text { Calculation } \\
\text { formula of } \\
\text { similarity } \\
\text { constant }\end{array}$ & $\begin{array}{r}\text { Similarity } \\
\text { constant }\end{array}$ \\
\hline Geometry size & $l$ & $\mathrm{~L}$ & $\alpha_{l}$ & 40 \\
\hline Bulk density & $\gamma$ & $\mathrm{ML}^{-2} \mathrm{~T}^{-2}$ & $\alpha_{\gamma}$ & 1 \\
\hline $\begin{array}{l}\text { Permeability } \\
\text { coefficient }\end{array}$ & $k$ & $\mathrm{LT}^{-1}$ & $\alpha_{k}$ & 1 \\
\hline $\begin{array}{l}\text { Seepage } \\
\text { discharge }\end{array}$ & Q & $\mathrm{L}^{3} \mathrm{~T}^{-1}$ & $\alpha_{Q}=\alpha_{l}^{2} \times \alpha_{k}$ & 1600 \\
\hline Stress & $\sigma$ & $\mathrm{ML}^{-1} \mathrm{~T}^{-2}$ & $\alpha_{\sigma}=\alpha_{\gamma} \times \alpha_{l}$ & 40 \\
\hline $\begin{array}{l}\text { Elastic } \\
\text { modulus }\end{array}$ & $E$ & $\mathrm{ML}^{-1} \mathrm{~T}^{-2}$ & $\alpha_{E}=\alpha_{\gamma} \times \alpha_{l}$ & 40 \\
\hline Time & $t$ & $\mathrm{~T}$ & $\alpha_{t}=\alpha_{l} / \alpha_{k}$ & 40 \\
\hline
\end{tabular}

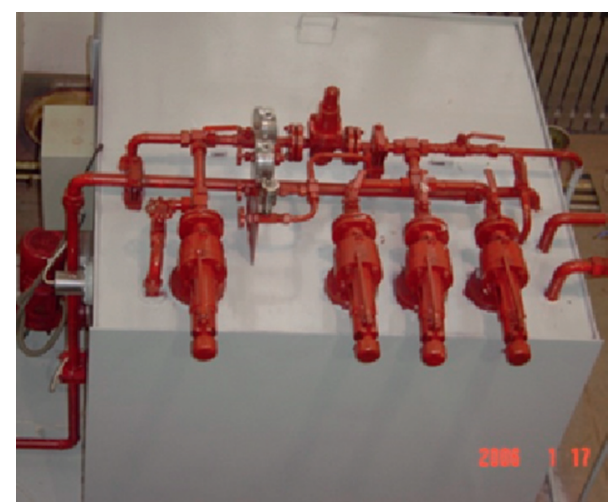

FIGURE 14: Water pressure control system diagram. model test rack and prototype tunnel size, the similarity constant of bulk density $\alpha_{\gamma}=1$, geometric dimension similarity constant $\alpha_{l}=40$ and permeability coefficient similarity constant $\alpha_{k}=1$ were determined in the model test.

The main loads borne by the Gongbei tunnel structure are earth pressure and water pressure. Combined with the hydraulic system and the self weight of the surrounding rock similar material, the earth pressure was applied in the model. The water pressure was applied by the water pressure control system.According to the similarity theory and the model test principle, the vault water pressure is $0.075 \mathrm{kPa}$, and the calculated vault soil thickness is $0.125 \mathrm{~m}$.

4.1.3. Test Materials. According to the previous geotechnical test experience of similar materials of the surrounding rock [38-41], the original sample soil is firstly sampled and tested. The original sample soil is mainly from the silty clay of layer (3)-2. The results of the geotechnical test are shown in $\mathrm{Ta}$ ble 3 . Then, the soil around Beijing was investigated, and the soil similar to the surrounding rock was determined as the model soil material. The method of adding barite powder and double flying powder to the model soil material was used to simulate the surrounding rock. The specific operation was to determine the physical and the mechanical properties of the model material after mixing according to different proportions, and compare with the material indexes of the original soil. Finally, the mix proportion meeting the similar conditions was determined. The physical and the mechanical indexes of the model material and the prototype material are shown in Table 3.

According to the above geotechnical test results of similar material of the surrounding rock, the physical and the mechanical parameters were obtained, and the calculation formula of the similarity criterion number determined by the similarity theory and the model test principle was substituted. Finally, the similarity criterion number in model test: $\alpha_{\gamma}=1.06 \approx 1, \alpha_{k}=0.91 \approx 1$. The selection of similar material of the surrounding rock met the similarity criterion of model test very well.

The grouting ring was simulated by mixing the similar materials of the surrounding rock and the cement water glass solution in a certain proportion, and the permeability coefficient was about $1 / 10$ of the similar material of the surrounding rock, which conformed to the permeability characteristics of the grouting material. The pipe roof was simulated by PVC pipes, as shown in Figure 15. The pipe diameter is about $5 \mathrm{~cm}$, and the odd pipes were filled with cement mortar.

In the prototype project, the initial support is composed of shotcrete, steel mesh, and I-steel, and the secondary lining is composed of light-steel formwork concrete, and the tertiary lining is composed of reinforced concrete. It is difficult to achieve complete similarity of the above supporting structures in the model test. Therefore, the support structures in the model were simplified to be as similar as possible to the prototype project. According to the similarity principle of model test, the material selection of the Gongbei tunnel structure model is shown in Table 4. The elastic 
TABLE 3: Ratio of main physical and mechanical indexes between the prototype materials and the model materials.

\begin{tabular}{lccccc}
\hline Soil layer & Object & Natural density $\left(\mathrm{g} / \mathrm{m}^{3}\right)$ & Void ratio & Compression modulus $(\mathrm{MPa})$ & Permeability coefficient $(\mathrm{cm} / \mathrm{s})$ \\
\hline & Prototype material & 1.98 & 0.71 & 4.91 & $1.82 \times 10^{-3}$ \\
Layer (3)-2 & Model material & 1.87 & 0.62 & 0.16 & $2.00 \times 10^{-3}$ \\
& Similar proportion & 1.06 & 0.80 & 30.2 & 0.91 \\
\hline
\end{tabular}

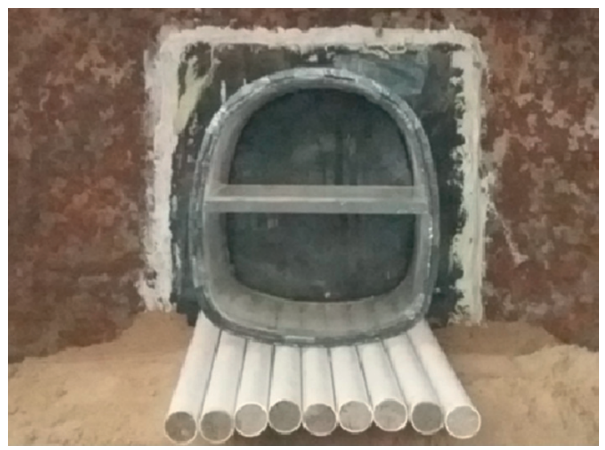

FIGURE 15: Indoor similarity test model.

TABLE 4: Comparison table of the tunnel support structure prototype materials and the model materials.

\begin{tabular}{|c|c|c|c|c|c|}
\hline Object & & Initial support & & Secondary lining & Third lining \\
\hline $\begin{array}{l}\text { Prototype } \\
\text { material }\end{array}$ & $\begin{array}{c}\text { C25 shotcrete } 30 \mathrm{~cm} \\
\text { with a thickness of } \\
40 \mathrm{~cm}\end{array}$ & $\begin{array}{c}\text { Double layer } \\
20 \mathrm{~cm} \times 20 \mathrm{~cm} \text { of steel } \\
\text { mesh }\end{array}$ & $\begin{array}{l}\text { I22b I-steel with a } \\
\text { spacing of } 40 \mathrm{~cm}\end{array}$ & $\begin{array}{l}\text { C35 formwork concrete } \\
\text { with a thickness of } 30 \mathrm{~cm}\end{array}$ & $\begin{array}{l}\text { C50 reinforced } \\
\text { concrete }\end{array}$ \\
\hline $\begin{array}{l}\text { Model } \\
\text { material }\end{array}$ & $\begin{array}{c}\text { C25 cement mortar } \\
\text { with a thickness of } \\
0.75 \mathrm{~cm}\end{array}$ & Fine wire mesh & $\begin{array}{c}\text { 4-mm diameter steel } \\
\text { bar with a spacing of } \\
1 \mathrm{~cm}\end{array}$ & $\begin{array}{l}\text { C35 cement mortar with } \\
\text { a thickness of } 0.75 \mathrm{~cm}\end{array}$ & $\begin{array}{l}\text { Plexiglass with a } \\
\text { thickness of } 1.8 \mathrm{~cm}\end{array}$ \\
\hline
\end{tabular}

modulus of PMMA at $14^{\circ} \mathrm{C}$ is $2760.2 \mathrm{MPa}$, about $1 / 10$ of the concrete, which basically meets the test requirements.

4.1.4. Test Content and Monitoring Scheme. The tertiary lining model was simulated with plexiglass material, with waterproof board on the surface and blind drainage pipes. The annular blind pipes were made of thin plastic pipes and wrapped with gauze to prevent sand from flowing into the pipes, and a large number of water inlets were set on the outer wall of the annular blind pipes. Six drainage outlets were set on both sides of the model lining structure, with a total of 12 drainage outlets. After the 12 drainage pipes were led out, they were connected through a faucet, which was convenient to test the water discharge and control the size of the water discharge. The arrangement of the water pressure test points is shown in Figure 16. In the test, due to the symmetry of the model, the water pressure measuring points were arranged symmetrically and alternately to reduce the influence of the water pipes on the surrounding rock and the seepage field. The water pressure on the upper surface of the upper pipe roof was taken as the water head pressure standard. During the test, the pressure head increased from $0.5 \mathrm{kPa}$ to $6 \mathrm{kPa}$ under the condition of the variable head. Under each pressure of the water heads, different drainage flow groups were set by controlling the drainage pipes, which were full drainage, limited drainage 1, limited drainage 2 , limited drainage 3 , and full plugging. The water discharge capacity of each group is determined according to the specific operation of the test.

\subsection{Test Results and Analysis}

4.2.1. Free Water Discharge of the Tunnel under the Variable Head Pressure. When the external water head pressure changes according to $0.50 \mathrm{kPa}, 0.75 \mathrm{kPa}, 1.5 \mathrm{kPa}, 2 \mathrm{kPa}$, $3 \mathrm{kPa}, 4 \mathrm{kPa}, 5 \mathrm{kPa}$, and $6 \mathrm{kPa}$, the free water discharge of the tunnel model is shown in Figure 17.

It can be seen from Figure 17 that when the external water head is $0.50 \mathrm{kPa}$, the free water discharge in the tunnel is $4.0 \mathrm{ml} / \mathrm{s}$. When the external water head is $6 \mathrm{kPa}$, the free water discharge in the tunnel reaches $27.2 \mathrm{ml} / \mathrm{s}$. The free water discharge of the tunnel changes with the change of the external water head, and the relationship between them shows a parabola trend. In a certain range, the greater the external water head, the greater the free water discharge in the tunnel. When the external water head changes from $4 \mathrm{kPa}$ to $6 \mathrm{kPa}$, the increment of free water discharge in the tunnel is relatively small.

The amount of free water discharge in the tunnel is controlled by many factors, such as external water pressure, tunnel drainage conditions and the ability of the drainage system, the permeability of the tunnel surrounding the rock, etc. When the external water pressure of the lining is less than the capacity of the tunnel drainage system, the increase 


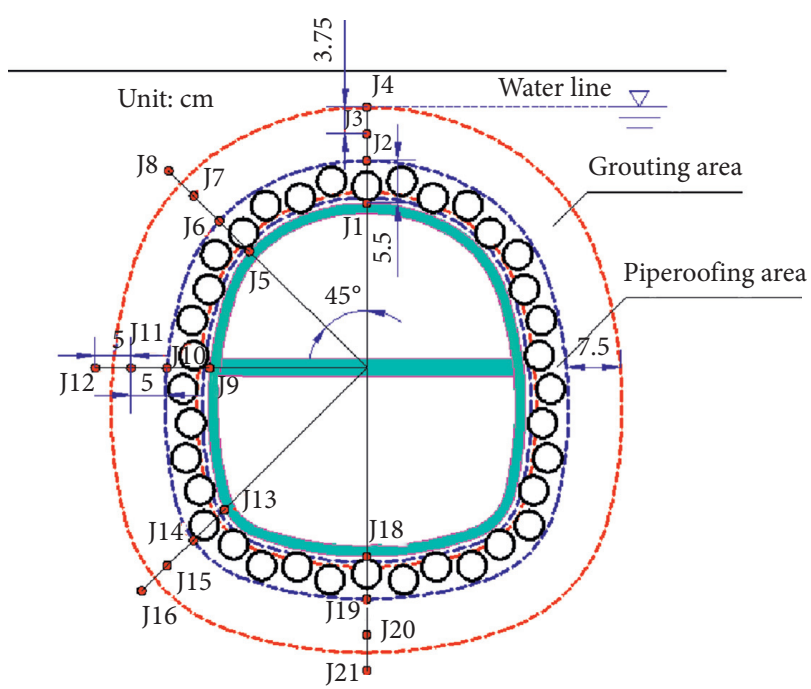

FIGURE 16: Layout of the water pressure measuring points.

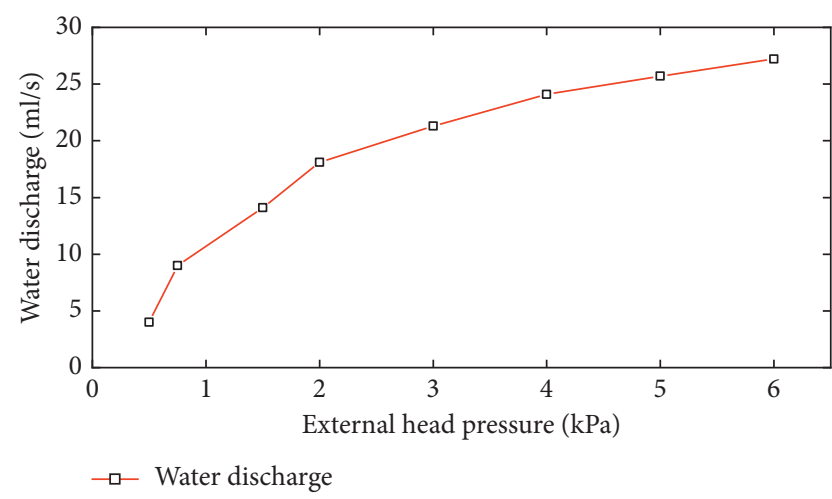

FIGURE 17: Relationship between the head pressure and the free drainage of the tunnel.

of the external water pressure of the lining may increase the free water discharge of the tunnel. When the external water pressure of the lining increases to greater than the capacity of the tunnel drainage system, the free water discharge of the tunnel may tend to be constant, which is the maximum drainage capacity of the tunnel.

It is worth noting that this test is to measure the free water discharge of the tunnel under variable head pressure. On the one hand, it is to study the variation law of the tunnel free drainage under external variable head pressure; on the other hand, it is to provide the basis for determining the following limited drainage conditions.

4.2.2. Relationship between the Water Pressure and the Discharge outside the Pipe Roof and the Lining. Based on the study of the relationship between the external water head pressure and the free water discharge in the tunnel, the water discharge under each test condition is determined, as shown in Table 5, when the external water head pressure is $0.75 \mathrm{kPa}$. The test conditions are named as full drainage, limited drainage condition 1 , limited drainage condition 2 , limited drainage condition 3 , and full plugging.
Typical measuring points outside the pipe roof and the lining are selected as the research objects. The relationship between the water pressure outside the pipe roof and the water discharge is shown in Figure 18, and the relationship between the water pressure outside the lining and the water discharge is shown in Figure 19.

It can be seen from Figure 18 that the water pressure measured outside the pipe roof at the invert is the largest, and the water pressure outside the pipe roof at the vault is the minimum. The greater the water drainage of the tunnel is, the smaller the water pressure outside the pipe roof is. When the water discharge is $0 \mathrm{ml} / \mathrm{s}$, the water pressure outside the pipe roof is $0.72-6.83 \mathrm{kPa}$. When the water discharge is $9.0 \mathrm{ml} / \mathrm{s}$, the water pressure outside the pipe roof is $0.50-4.78 \mathrm{kPa}$. With the increase of water discharge, the decrease of water pressure outside the pipe roof at the invert is the largest, and that at the vault is the smallest. It can be seen from Figure 19 that the variation law of the water pressure outside the lining with the increase of the water discharge is consistent with that of the water pressure outside the pipe roof. With the increase of the water discharge, the water pressure outside the lining decreases gradually. The decrease in the degree of external water pressure of the arch lining is less than that of the invert lining. When the water discharge is $0 \mathrm{ml} / \mathrm{s}$, the water pressure outside the lining is $1.32-6.25 \mathrm{kPa}$. When the water discharge is $9.0 \mathrm{ml} / \mathrm{s}$, the water pressure outside the lining is $0.66-3.13 \mathrm{kPa}$.

The larger is the tunnel water discharge, the smaller is the water pressure outside the pipe roof and the lining, which is consistent with the conclusion of the existing research [42]. When the tunnel is fully drained, the water pressure outside the pipe roof is still greater than that outside the lining. The main reason is that the drainage pipe is basically arranged close to the lining, while the underground seepage field has a certain gradient, and the water pressure near the drainage outlet is small, resulting in a large difference in the water pressure. In addition, due to the existence of the pipe roof, the permeability coefficient of the pipe roof area is lower than that of grouting area, and the flow hindrance of the groundwater in the pipe roof area is greater. Therefore, the water pressure outside the lining is smaller than that of the pipe roof when the tunnel adopts full drainage measures.

\subsubsection{Distribution of the Water Pressure and the Seepage} Field around the Tunnel. In order to correspond to the actual project, the test group with the external water head pressure of $0.75 \mathrm{kPa}$ was taken as the research object. The variation of the water pressure at the measuring points above the tunnel vault with the distance from the tunnel vault is shown in Figure 20. The water pressure at the horizontal measuring point outside the tunnel varies with the horizontal distance from the tunnel side wall as shown in Figure 21 . The water pressure at the measuring point below the tunnel invert varies with the distance from the tunnel invert as shown in Figure 22.

It can be seen from Figure 20 that when water plugging measures are adopted, the external water pressure above the 
TABLE 5: Flow chart of each test group with $0.75 \mathrm{kPa}$ water head pressure.

\begin{tabular}{|c|c|c|c|c|c|}
\hline $\begin{array}{l}\text { Test } \\
\text { groups }\end{array}$ & $\begin{array}{c}\text { Full } \\
\text { drainage }\end{array}$ & $\begin{array}{c}\text { Case } 2 \\
\text { Limited } \\
\text { drainage } \\
\text { condition } \\
1\end{array}$ & $\begin{array}{c}\text { Case } 3 \\
\text { Limited } \\
\text { drainage } \\
\text { condition } \\
2 \\
\end{array}$ & $\begin{array}{c}\text { Case } 4 \\
\text { Limited } \\
\text { drainage } \\
\text { condition } \\
3 \\
\end{array}$ & $\begin{array}{c}\text { Case } 5 \\
\\
\text { Full } \\
\text { plugging }\end{array}$ \\
\hline $\begin{array}{l}\text { Flow } \\
(\mathrm{ml} / \mathrm{s})\end{array}$ & 9.0 & 4.5 & 2.5 & 1.5 & 0 \\
\hline
\end{tabular}

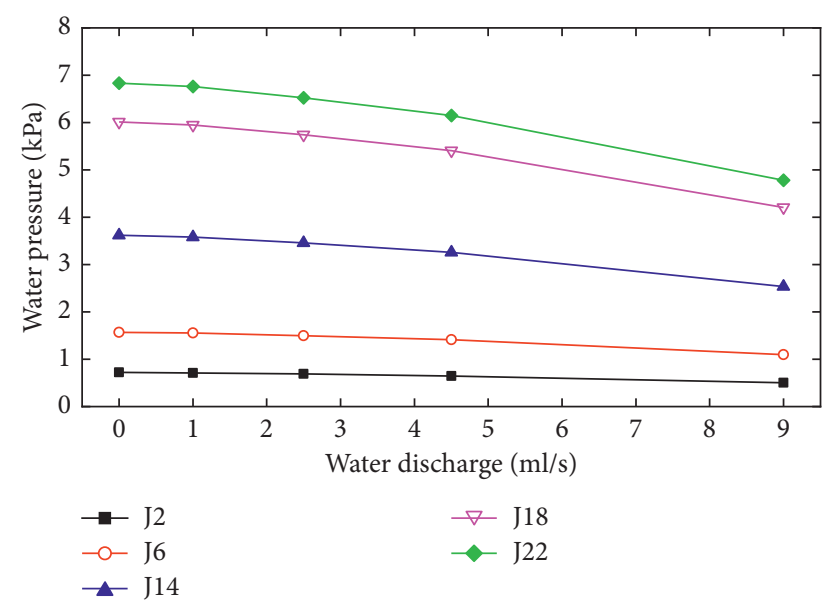

FIGURE 18: Relationship between the water pressure outside the pipe roof and the water discharge.

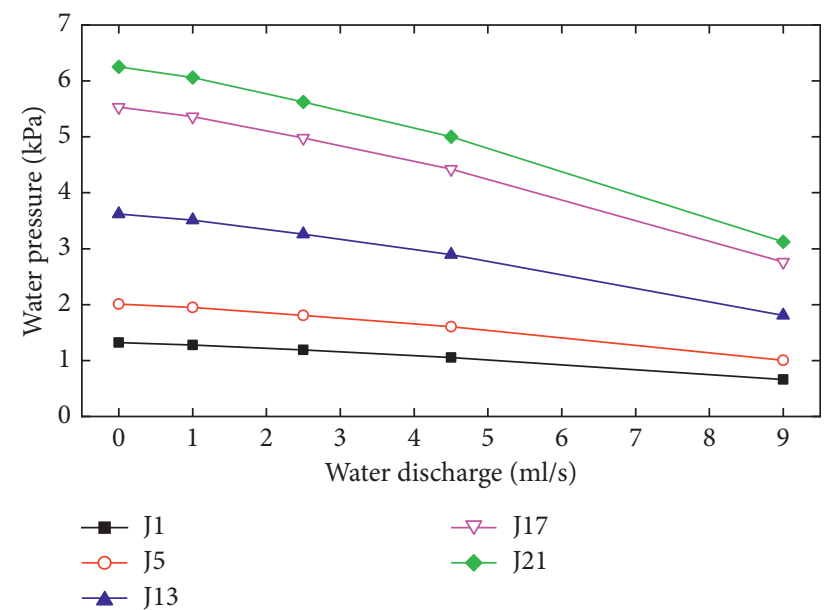

FIGURE 19: Relationship between the water pressure outside the lining and the water discharge.

tunnel basically conforms to the distribution law of the hydrostatic water. When the drainage measures were adopted in the tunnel, even if the water discharge was very small, the external water pressure of the tunnel was basically less than the hydrostatic pressure, and the greater the water discharge, the smaller the external water pressure of the tunnel. When the tunnel adopts drainage measures, the closer the tunnel is to the vault, the greater the reduction of water pressure.. The greater the water discharge, the greater the reduction of the water pressure in the pipe roof area and the grouting area. In general, the decrease of the water pressure in the grouting area above the tunnel was less than that in the pipe roof area under the drainage condition. The results show that the external water pressure outside the tunnel vault lining was $0.66 \mathrm{kPa}$, while the hydrostatic pressure of the same water level was $1.32 \mathrm{kPa}$, and the water pressure outside the lining was only $50 \%$ of the hydrostatic pressure. The results show that the water pressure at the junction of the pipe roof area and the grouting area was $0.50 \mathrm{kPa}$, the hydrostatic pressure of the same water level was $0.72 \mathrm{kPa}$, and the water pressure was $69.4 \%$ of the hydrostatic pressure.

It can be seen from Figure 21 that the distribution law of the water pressure outside of tunnel side wall mainly shows that with the increase of drainage, the water pressure in the pipe roof area and grouting area decreases, and the greater the water discharge, the greater the degree of water pressure reduction. The decrease in the degree of the water pressure in the pipe roof area was greater than that in the grouting area. With the increase in the distance from the side wall of the tunnel, the water pressure increased gradually. At $15.5 \mathrm{~cm}$ away from the side wall of the tunnel, the water pressure was the same as the hydrostatic pressure. When the tunnel was fully drained, the external water pressure outside the tunnel side wall lining was $1.80 \mathrm{kPa}$, the hydrostatic pressure of the same water level was $3.62 \mathrm{kPa}$, and the water pressure outside the lining was $49.7 \%$ of the hydrostatic pressure. The results show that the water pressure at the junction of the pipe roof area and the grouting area was $2.65 \mathrm{kPa}$, the hydrostatic pressure was $3.61 \mathrm{kPa}$, and the water pressure at the junction of the pipe roof area and grouting the area was about $73.41 \%$ of the hydrostatic pressure.

It can be seen from Figure 22 that the distribution law of the water pressure under the tunnel invert is similar to that outside the side wall, which mainly shows that with the increase of drainage, the water pressure in the pipe roof area and the grouting area decreases, and the greater the water discharge, the greater the reduction degree of the water pressure. The decrease degree of the water pressure in the pipe roof area was greater than that in the grouting area. With the increase of the distance from the tunnel invert, the water pressure increased gradually. At $15.5 \mathrm{~cm}$ away from the invert of the tunnel, the water pressure was the same as the hydrostatic pressure. When the tunnel was fully drained, the external water pressure outside the tunnel invert lining was $3.13 \mathrm{kPa}$, the hydrostatic pressure at the same water level was $6.25 \mathrm{kPa}$, and the water pressure outside the lining was $50.1 \%$ of the hydrostatic pressure. When the tunnel was fully drained, the water pressure at the junction of the pipe roof area and the grouting area under the tunnel invert was $4.78 \mathrm{kPa}$, the hydrostatic pressure at the same water level was $6.83 \mathrm{kPa}$, and the water pressure was about $69.99 \%$ of the hydrostatic pressure.

The water pressure in the medium with uniform permeability will conform to the distribution of the hydrostatic pressure. Due to the grouting effect and the existence of the pipe roof, the permeability of the surrounding rock around the tunnel is reduced, which leads to the decrease of the 


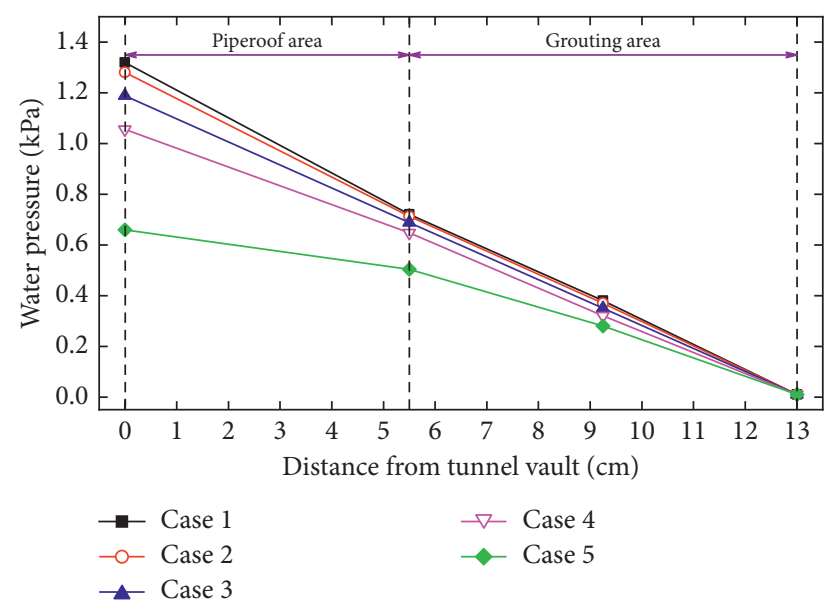

FIgURE 20: Variation curve of the water pressure above the tunnel vault with distance from the tunnel vault.

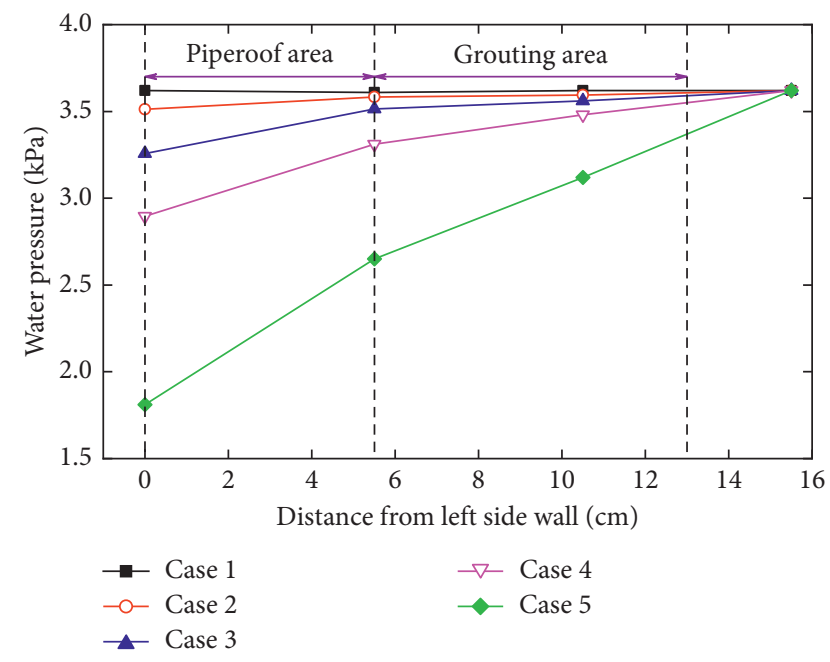

FIGURE 21: Variation curve of the water pressure outside the tunnel side wall with distance from the tunnel side wall.

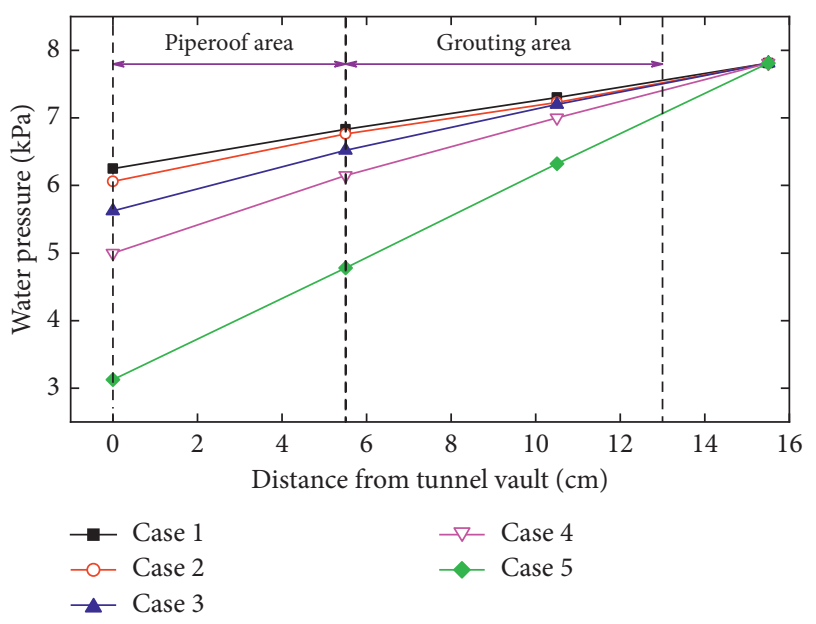

FIGURE 22: Variation curve of the water pressure under the tunnel invert with distance from the tunnel invert. water pressure in the pipe roof area and the grouting area under the drainage condition. The water pressure outside the grouting area basically conforms to the distribution of the hydrostatic pressure. When the tunnel adopts drainage measures, the greater the water discharge, the stronger the reduction of the water pressure in the pipe roof area. This may be due to the small permeability of the pipe roof area, which hinders the flow of water, resulting in the water in the pipe roof area not being discharged in time during drainage. The water velocity in the pipe roof area and the grouting area is small, the drainage speed is fast near the drainage outlet, and the water pressure decreases rapidly, resulting in a larger hydraulic gradient. When water plugging measures are employed in the tunnel, the water pressure at the different positions of the tunnel basically follows the distribution of the hydrostatic pressure. To sum up, when taking drainage measures, the calculation of water pressure should comprehensively consider the surrounding rock permeability coefficient, water level, grouting quality, pipe roof, and other factors. According to the analysis of indoor similar model test results, we suggest that the reduction factor of lining external water pressure should be $50 \%$ in the design of coastal tunnel such as Gongbei tunnel. The external water pressure of the tunnel lining is calculated according to the hydrostatic pressure when the tunnel is fully plugging.

\section{In Situ Monitoring of the Water Pressure in the Gongbei Tunnel}

5.1. Monitoring Instrument and Scheme. It can be seen from the discussion in Section 3 above that if the drainage system is adopted in the Gongbei tunnel, the drainage volume will be large, and the long-term drainage will affect the overall stability of the tunnel. Therefore, the Gongbei tunnel adopted the waterproof system of grouting ring + pipe roof freezing ring + initial support + secondary lining + waterproof board + tertiary lining, and there is no drainage during the operation. In order to study the waterproof and drainage system and the water pressure law of the Gongbei tunnel, the XJS- 6 pore water pressure sensor was used to monitor the external water pressure of the initial support of the Gongbei tunnel and the external water pressure of the waterproof board, as shown in Figure 23. This kind of pore water pressure sensor is developed on the basis of the old sensor. The sensor is made of stainless steel with less temperature influence. The vibrating wire element is installed in the sealed cavity, the vibrating wire is fixed by special technology, and the steel string is connected with a sensitive membrane, so that the liquid pressure can be converted into the same frequency signal measurement output. Membrane deformation is caused due to the change in the pressure, and the tension and the resonance frequency of the steel string are changed, so that each pressure has a corresponding frequency output. This kind of sensor has the advantages of small volume, high sensitivity, good stability, rapid response, easy to use, suitable for long-term observation, and suitable for monitoring the external water pressure of the Gongbei tunnel lining. The layout of the monitoring points is shown 
in Figure 24; eight measuring points were set at the outside of the primary support and the waterproof board.

5.2. Monitoring Results and Analysis. Figure 25 shows the curve of the change of the external water pressure of the initial support with time, and Figure 26 shows the curve of the water pressure outside the waterproof board changing with time.

It can be seen from Figure 25 that the water pressure outside the initial support increases at first and then tends to be stable with the construction going on, and the stable water pressure can be basically reached after 10 days of embedding the pore water pressure sensor. After the tunnel thawed, the water pressure increased. In general, the water pressure outside the initial vault support was the smallest, and the water pressure outside the initial vault support after thawing was about $53.6 \mathrm{kPa}$. The water pressure outside the initial invert support was the largest, and the water pressure of the invert was about $246.09 \mathrm{kPa}$ after the thawing of the frozen area, which was consistent with the model test. It can be seen from Figure 26 that the water pressure outside the tertiary lining increases firstly and then tends to be stable with the progress of construction. However, unlike the growth law of the water pressure outside the initial support, the water pressure outside the lining increased slowly, and the influence of the thawing process on the external water pressure of the lining was not obvious. In general, the water pressure outside the tunnel vault lining was the smallest, and the water pressure outside the tunnel vault lining was about $49.79 \mathrm{kPa}$ after thawing in the frozen area, and the water pressure outside the lining at the invert was the largest. The water pressure outside the lining after thawing in the frozen area was about $206.18 \mathrm{kPa}$, which was basically similar to the water pressure outside the initial support, but the value of the water pressure was relatively small.

The outside of the initial support of the tunnel is the pipe roof freezing ring and the grouting ring. During the excavation, the waterproof board and the tertiary lining was not applied, the external water could penetrate into the tunnel through the freezing ring and the grouting ring, which is equivalent to discharging a small amount of water. Therefore, the water pressure outside the tunnel initial support was relatively small during the construction period. The waterproof board was procured before the construction of the tertiary lining. Because of the waterproof effect of the grouting ring, the pipe roof freezing ring, the initial support and the secondary lining on the outside of the waterproof board, the water pressure outside the waterproof board rose slowly, and the water pressure stability value was relatively small compared with the water pressure outside the initial support during the monitoring period. However, after long-term groundwater movement, the water pressure outside the waterproof board should be close to the hydrostatic pressure theoretically.

5.3. Comparison and Verification between the Model Test Results and the Field Monitoring Results. It can be seen from Table 2 that the similarity ratio of similar model test mechanics is 40 . That is to say, a water pressure of $1 \mathrm{kPa}$ in the similar test result is equal to a water pressure of $40 \mathrm{kPa}$ in the actual project. The water pressure outside the pipe roof and the lining under the condition of no drainage in the indoor similar test was converted through the similarity ratio, and the water pressure section distribution was drawn as shown in Figure 27. At the same time, the water pressure distribution outside the initial support and the waterproof board in the field monitoring results was drawn in Figure 27, so as to compare and analyze the indoor test and the field monitoring results.

It can be seen from Figure 27 that there is little difference between the indoor test results and the field monitoring results, and the distribution law is the same, which roughly conforms to the law of the hydrostatic pressure. It is worth noting that the in situ monitoring value of the water pressure in the upper part of the tunnel is larger than that in the indoor model test, which may be due to the influence of the tide on the water level due to the nearshore location of the tunnel, thus affecting the in situ monitoring value of water pressure. The water pressure distribution in the lower part of the tunnel is contrary to the above rules, mainly because the stratum conditions in the indoor model test cannot be exactly the same as those in the field, the stratum conditions in the tunnel engineering field are more complex, the permeability of the stratum outside the tunnel is reduced due to grouting and other factors, and the external seepage field is not completely static. Therefore, it is reasonable to have the above rules.

Unfortunately, the excavation process is not considered in the laboratory test. At the initial stage of the test design, because the main object of the study is the water pressure outside the tunnel, we think that for this project, the tunnel excavation process has little impact on the water pressure, and it is not easy to realize the underwater tunnel indoor test excavation. Therefore, the time effect cannot be considered in the analysis of indoor test results. In fact, in situ monitoring of the water pressure changes is more complicated. Nevertheless, through the analysis of the indoor test results and the field monitoring results, it can be seen that the indoor test results have been verified by the field monitoring results, and the design of the indoor test is more reasonable, which largely reproduces the water pressure distribution of the Gongbei tunnel project. Furthermore, the above 


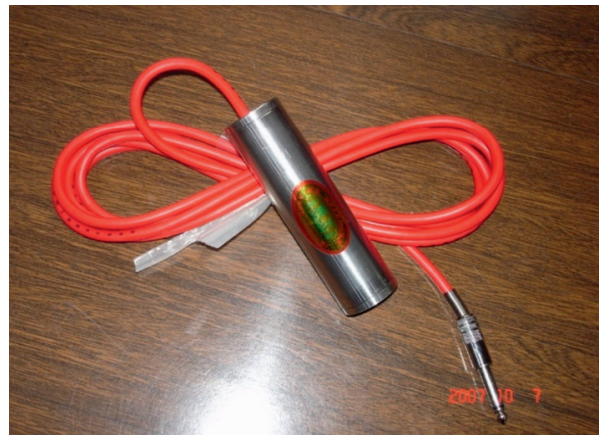

FIGURE 23: XJS-6 pore water pressure sensor.

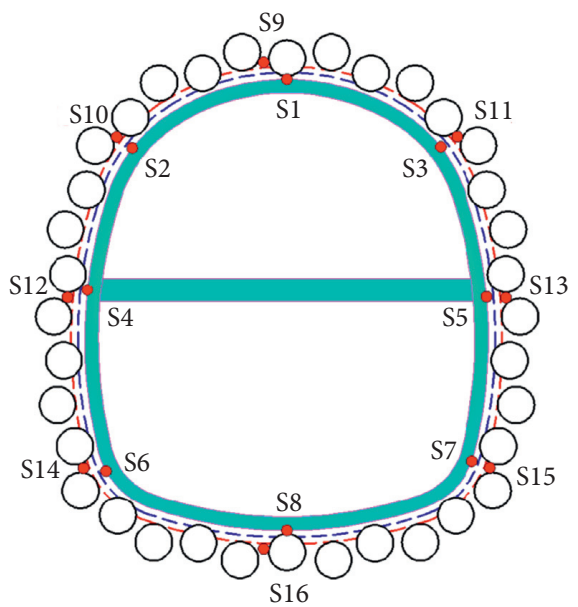

FIGURE 24: Layout of in situ monitoring points for the water pressure outside the tunnel.

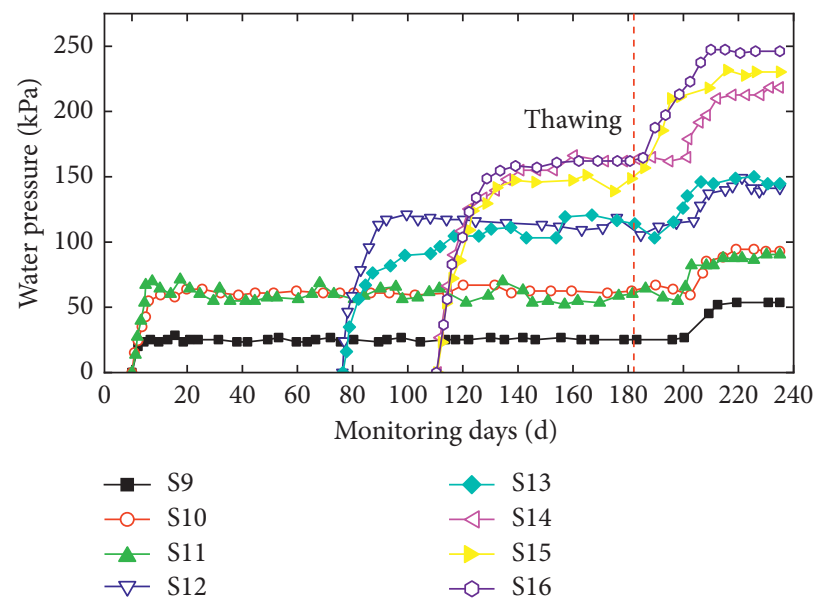

Figure 25: Water pressure outside the tunnel initial support. 


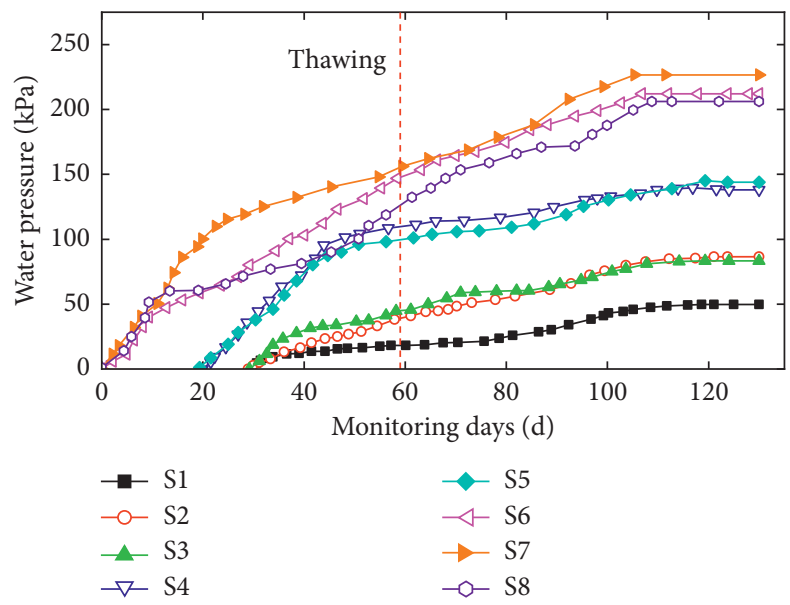

FIGURE 26: Water pressure outside the waterproof board.

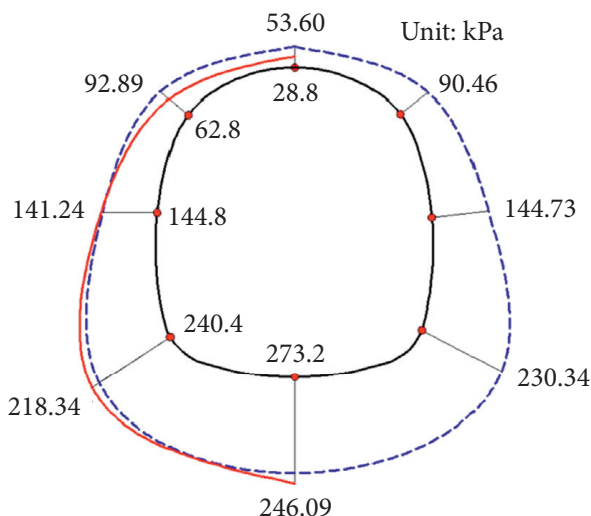

- Similar model test result curve

--- On site monitoring result curve

(a)

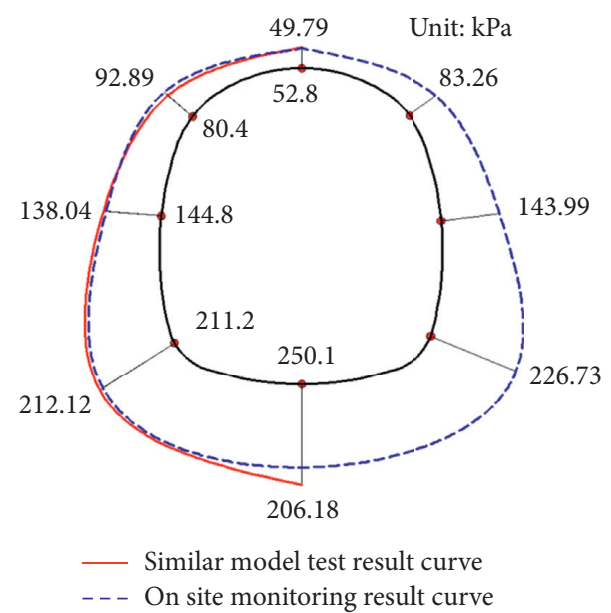

(b)

Figure 27: Comparison of indoor similar test and in situ monitoring results. (a) Water pressure outside the tunnel pipe roof and the initial support. (b) Water pressure outside the waterproof board and the lining.

conclusions obtained from the indoor experimental study can also provide a theoretical reference for the design of similar coastal tunnels.

\section{Conclusions}

In this paper, based on the Gongbei tunnel project, the waterproof and drainage system and water pressure outside the lining of the coastal tunnel are studied by indoor tests and field monitoring methods. The main conclusions are as follows:

(1) Based on the discussion of the waterproof and drainage system of the Gongbei tunnel, it is determined that the waterproof principle should be mainly used in the coastal tunnel. The waterproof and drainage system of the Gongbei tunnel is composed of grouting ring + pipe roof freezing ring + initial support + secondary lining + waterproof board + tertiary lining.
(2) The free water discharge of the tunnel changes with the change of the external water head, and the relationship between them shows a parabola trend. In a certain range, the greater the internal and external water heads, the greater the free water discharge in the tunnel. The indoor similarity test results show that when the external water head changes from $4 \mathrm{kPa}$ to $6 \mathrm{kPa}$, the increment of free water discharge in the tunnel is relatively small.

(3) The water pressure outside the pipe roof at the invert is the largest, and that at the vault is the minimum. The greater the tunnel water discharge, the smaller the water pressure outside the pipe roof. With the increase of the water discharge, the decrease of the water pressure outside the pipe roof at the invert is the largest, and that at the vault is the smallest. The decrease degree of the external water pressure outside the tunnel vault lining is less than that outside the tunnel invert lining. 
(4) When the water plugging measures are adopted in the tunnel, the external water pressure above the tunnel basically conforms to the distribution law of the hydrostatic water. When the tunnel adopts drainage measures, even if the water discharge is very small, it also has a certain impact on the water pressure outside the tunnel. Under the drainage condition, the water pressure outside the tunnel is less than the hydrostatic pressure, and the greater the water discharge, the smaller the water pressure outside the tunnel.

(5) When the tunnel is drained, the closer the distance from the tunnel, the greater the reduction of the water pressure. The greater the water discharge, the greater the reduction of the water pressure in the pipe roof area and the grouting area. In general, the decrease of the water pressure in the grouting area above the tunnel is less than that in the pipe roof area under the drainage condition. The water pressure outside the lining is only $49.1-50.1 \%$ of the hydrostatic pressure. The water pressure at the junction of the pipe roof area and the grouting area is $69.4-73.4 \%$ of the hydrostatic pressure.

(6) The water pressure outside the initial support increases initially and then tends to be stable with the construction going on. After 10 days of embedding the pore water pressure sensor, the stable water pressure can be basically achieved. After the tunnel thawed, the water pressure increased. The field monitoring results are consistent with the model test results. The water pressure outside the lining increases initially and then tends to be stable with the progress of construction. The increase of the water pressure outside the lining is relatively slow, and the influence of the thawing process on the water pressure outside the lining is not obvious.

\section{Data Availability}

The data used to support the findings of this study are included within the article.

\section{Conflicts of Interest}

The authors declare that they have no conflicts of interest.

\section{Acknowledgments}

This work was supported by the National Natural Science Funds of China (Grant no. 51678034).

\section{References}

[1] T.-l. Chen, D.-l. Zhang, C. Zeng, and G.-g. Ying, "Application of new concept waterproofing in Xiang'an undersea tunnel, China," China Ocean Engineering, vol. 27, no. 1, pp. 121-130, 2013.

[2] K. Hong, "Typical underwater tunnels in the mainland of China and related tunneling technologies," Engineering, vol. 3, no. 6, pp. 871-879, 2017.
[3] D. Jin, D. Yuan, X. Li, and W. Su, "Probabilistic analysis of the disc cutter failure during TBM tunneling in hard rock," Tunnelling and Underground Space Technology, vol. 109, p. 103744, 2021.

[4] D. Jin, Z. Zhang, D. Yuan et al., "Effect of dynamic cutterhead on face stability in EPB shield tunneling," Tunnelling and Underground Space Technology, vol. 110, Article ID 103827, 2021.

[5] N. Kitterød, H. Colleuille, W. Wong et al., "Simulation of groundwater drainage into a tunnel in fractured rock and numerical analysis of leakage remediation, Romeriksporten tunnel, Norway," Hydrogeol Journal, vol. 8, no. 5, pp. 480-493, 2000.

[6] S. Türkmen, "Water leakage from the power tunnel of Gezende Dam, southern Turkey: a case study," Environmental Earth Sciences, vol. 61, no. 2, pp. 419-427, 2010.

[7] K. K. Panthi and B. Nilsen, "Uncertainty analysis for assessing leakage through water tunnels: a case from Nepal himalaya," Rock Mechanics and Rock Engineering, vol. 43, no. 5, pp. 629-639, 2010.

[8] Y. Fang, J. Guo, J. Grasmick, and M. Mooney, "The effect of external water pressure on the liner behavior of large cross-section tunnels," Tunnelling and Underground Space Technology, vol. 60, pp. 80-95, 2016.

[9] V. F. Ilyushin and V. M. Nasberg, "Full-scale investigations of ground-water pressure on tunnel linings," Hydrotechnical Construction, vol. 9, no. 4, pp. 342-345, 1975.

[10] National Civil Air Defense Office, Technical Code for Waterproofing of Underground Engineering, China Planning Press, Beijing, China, 2001.

[11] Y. Zhuo, Study on waterproof and drainage theory and application of drilling and blasting method for shallow underwater tunnel, $\mathrm{PhD}$ thesis, Beijing Jiaotong University, Beijing, China, 2013.

[12] Ø. Dammyr, B. Nilsen, K. Thuro, and J. Grøndal, "Possible concepts for waterproofing of Norwegian TBM Railway tunnels," Rock Mechanics and Rock Engineering, vol. 47, no. 3, pp. 985-1002, 2014.

[13] P. Cheng, L.-h. Zhao, L. Li, J.-f. Zou, and W. Luo, "Limiting drainage criterion for groundwater of mountain tunnel," Journal of Central South University, vol. 21, no. 12, pp. 4660-4668, 2014.

[14] Y. Yuan, X. Jiang, and C. F. Lee, "Tunnel waterproofing practices in China," Tunnelling and Underground Space Technology, vol. 15, no. 2, pp. 227-233, 2000.

[15] S. Li, H. Tian, Y. Xue et al., "Study on major construction disasters and controlling technology at the qingdao kiaochow bay subsea tunnel," Journal of Coastal Research, vol. 73, pp. 403-409, 2015.

[16] P. Shi, D. Zhang, J. Pan, and W. Liu, "Geological investigation and tunnel excavation aspects of the weakness zones of Xiang'an subsea tunnels in China," Rock Mechanics and Rock Engineering, vol. 49, no. 12, pp. 4853-4867, 2016.

[17] Z. Xu, X. Wang, S. Li, B. Gao, S. Shi, and X. Xu, "Parameter optimization for the thickness and hydraulic conductivity of tunnel lining and grouting rings," KSCE Journal of Civil Engineering, vol. 23, no. 6, pp. 2772-2783, 2019.

[18] X. Xie, H. Chen, X. Xiao et al., "Study on seepage field and lining external water pressure of different drainage schemes in deep-buried diversion tunnel," Hunan Daxue Xuebao, vol. 45, no. S1, pp. 64-68, 2018, in Chinese.

[19] A. Ponlawich, J. Jae-Hyeung, K.. Chang-Yong et al., "Effect of drainage conditions on porewater pressure distributions and 
lining stresses in drained tunnels," Tunnelling and Underground Space Technology, vol. 24, no. 4, pp. 376-389, 2009.

[20] Z. Zhang, M. Huang, C. Wang et al., "Analysis and calculation of lining water pressure of high water pressure karst tunnel," IOP Conference Series: Earth and Environmental Science, vol. 510, no. 5, pp. 5-6, 2020.

[21] Y. Huang, Z. Fu, J. Chen, Z. Zhou, and J. Wang, "The external water pressure on a deep buried tunnel in fractured rock," Tunnelling and Underground Space Technology, vol. 48, no. apr, pp. 58-66, 2015.

[22] Y. Ma, J. Yang, Y. Wang et al., "Analysis of lining water pressure of high-pressure water-rich karst tunnel based on fluid-structure interaction," International Journal of Earth Sciences and Engineering, vol. 9, no. 5, pp. 2089-2095, 2016.

[23] Q. Yan, C. Zhang, W. Wu, Y. Zhang, and T. Ma, "Analytical solution for the external stress acting on the lining in a deep-buried circular TBM tunnel considering the seepage field," Journal of Applied Mechanics and Technical Physics, vol. 60, no. 1, pp. 176-185, 2019.

[24] Z. Shen, "Study on characteristics of water pressure on the second lining for high water level karst tunnel based on long term monitoring," Journal of the China Railway Society, vol. 37, no. 11, pp. 110-116, 2015, in Chinese.

[25] Y. Liu, Y. Feng, M. Xu, Y. Zhang, H. Long, and H. Zhu, "Effect of an incremental change in external water pressure on tunnel lining: a case study from the Tongxi karst tunnel," Natural Hazards, vol. 98, no. 2, pp. 343-377, 2019.

[26] A. Luciani and D. Peila, "Tunnel waterproofing: available technologies and evaluation through risk analysis," International Journal of Civil Engineering, vol. 17, no. 1, pp. 45-59, 2019.

[27] C. Gokdemir, Y. Rubin, X. Li et al., "Vulnerability analysis method of vegetation due to groundwater table drawdown induced by tunnel drainage," Advances in Water Resources, vol. 133, pp. 103-406, 2019.

[28] X. Jin, Y. Li, Y. Luo et al., "Prediction of city tunnel water inflow and its influence on overlain lakes in karst valley," Environmental Earth Sciences, vol. 75, no. 16, p. 1162, 2016.

[29] S. Ye and J. Yan, "Study on the waterproofing and drainage system of qingdao jiaozhou bay undersea tunnel," Modern Tunnelling Technology, vol. 47, no. 3, pp. 18-23, 2010, in Chinese.

[30] W. Tao, "Theoretical basis and engineering practice of tunnel waterproof and drainage principle of mainly plugging and limited discharge," Railway Standard Design, vol. 9, no. 1, pp. 78-82, 2006, in Chinese.

[31] Q. Liu, Structural waterproofing and drainage tachnlolgy of large section near sea tunnel, $\mathrm{PhD}$ thesis, Beijing Jiaotong University, Beijing, China, 2016.

[32] G. Li, C. Wang, G. Wang et al., "Effect of the blocking water and limiting discharge and surrounding rock permeability on the stability of subsea tunnel," Geotechnical and Geological Engineering, vol. 9, no. 19, pp. 1-16, 2020.

[33] D. Zhang, Q. Fang, and H. Lou, "Grouting techniques for the unfavorable geological conditions of Xiang'an subsea tunnel in China," Journal of Rock Mechanics and Geotechnical Engineering, vol. 6, no. 5, pp. 438-446, 2014.

[34] J. Hu, Y. Liu, Y. Li et al., "Artificial ground freezing in tunnelling through aquifer soil layers: a case study in nanjing metro line 2," KSCE Journal of Civil Engineering, vol. 22, no. 2, pp. 4136-4142, 2018.

[35] H. Ren, X. Hu, Z. Hong et al., "Experimental study on active freezing scheme of freeze-sealing pipe roof used in ultra-shallow buried tunnels," Yantu Gongcheng Xuebao, vol. 41, no. 2, pp. 320-328, 2019, in Chinese.

[36] Z. Zhou, Z. Tan, Q. Liu, J. Zhao, and Z. Dong, "Experimental investigation on mechanical characteristics of waterproof system for near-sea tunnel: a case study of the Gongbei tunnel," Symmetry, vol. 12, no. 9, p. 1524, 2020.

[37] Y. Zhang, F. T. Yue, R. J. Shi et al., "Study on the simulated testing on repairing drainage pipe of connecting passage of metro tunnel with the method of liquid nitrogen freezing," Advanced Materials Research, vol. 368, no. 10, pp. 2581-2585, 2012.

[38] Q. Tian, J. Zhang, and Y. Zhang, "Similar simulation experiment of expressway tunnel in karst area," Construction and Building Materials, vol. 176, no. 10, pp. 1-13, 2018.

[39] Q.-y. Zhang, M.-y. Ren, K. Duan et al., "Geo-mechanical model test on the collaborative bearing effect of rock-support system for deep tunnel in complicated rock strata," Tunnelling and Underground Space Technology, vol. 91, no. 9, Article ID 103001, 2019.

[40] H. M. Shahin, T. Nakai, K. Ishii et al., "Investigation of influence of tunneling on existing building and tunnel: model tests and numerical simulations," Acta Geotechnica, vol. 11, no. 6, pp. 679-692, 2016.

[41] Y. Fang, Z. Chen, L. Tao, J. Cui, and Q. Yan, "Model tests on longitudinal surface settlement caused by shield tunnelling in sandy soil," Sustainable Cities and Society, vol. 47, no. 5, Article ID 101504, 2019.

[42] L. Wu and P. Liu, "Study on lining external water pressure under limited discharge in deep buried tunnel," Carsologica Sinica, vol. 28, no. 3, pp. 288-292, 2009, in Chinese. 